\title{
High-throughput gene-expression quantification of grapevine defense responses in the field using microfluidic dynamic arrays
}

${\text { Marie-Cécile Dufour }{ }^{1 *} \text {, Noël Magnin }{ }^{1} \text {, Bernard Dumas }}^{2,3}$, Sophie Vergnes ${ }^{2,3}$ and Marie-France Corio-Costet ${ }^{1}$

\begin{abstract}
Background: The fight against grapevine diseases due to biotrophic pathogens usually requires the massive use of chemical fungicides with harmful environmental effects. An alternative strategy could be the use of compounds able to stimulate plant immune responses which significantly limit the development of pathogens in laboratory conditions. However, the efficiency of this strategy in natura is still insufficient to be included in pest management programs. To understand and to improve the mode of action of plant defense stimulators in the field, it is essential to develop reliable tools that describe the resistance status of the plant upon treatment.
\end{abstract}

Results: We have developed a pioneering tool ("NeoViGen96" chip) based on a microfluidic dynamic array platform allowing the expression profiling of 85 defense-related grapevine genes in $90 \mathrm{CDNA}$ preparations in a $4 \mathrm{~h}$ single run. Two defense inducers, benzothiadiazole (BTH) and fosetyl-aluminum (FOS), have been tested in natura using the "NeoViGen96" chip as well as their efficacy against downy mildew.

BTH-induced grapevine resistance is accompanied by the induction of PR protein genes (PR1, PR2 and PR3), genes coding key enzymes in the phenylpropanoid pathway (PAL and STS), a GST gene coding an enzyme involved in the redox status and an ACC gene involved in the ethylene pathway.

FOS, a phosphonate known to possess a toxic activity against pathogens and an inducing effect on defense genes provided a better grapevine protection than BTH. Its mode of action was probably strictly due to its fungicide effect at high concentrations because treatment did not induce significant change in the expression level of selected defense-related genes.

Conclusions: The NeoViGen96" chip assesses the effectiveness of plant defense inducers on grapevine in vineyard with an excellent reproducibility. A single run with this system ( $4 \mathrm{~h}$ and 1,500 €), corresponds to $180 \mathrm{gPCR}$ plates with conventional Q-PCR assays (Stragene system, $270 \mathrm{~h}$ and 9,000 $€$ ) thus a throughput 60-70 times higher and 6 times cheaper. Grapevine responses after BTH elicitation in the vineyard were similar to those obtained in laboratory conditions, whereas our results suggest that the protective effect of FOS against downy mildew in the vineyard was only due to its fungicide activity since no activity on plant defense genes was observed. This tool provides better understanding of how the grapevine replies to elicitation in its natural environment and how the elicitor potential can be used to reduce chemical fungicide inputs.

Keywords: BTH, Defense responses, Dynamic array, Elicitation, Fosetyl, Gene expression, Grapevine, Real-time qPCR, Vineyard experiments, Plasmopara viticola

\footnotetext{
* Correspondence: dufour@bordeaux.inra.fr

'INRA, UMR Santé et Agroécologie du vignoble (SAVE-1065), CS 20032, ISW,

33882 Villenave d'Ornon, CEDEX, France

Full list of author information is available at the end of the article
}

(c) The Author(s). 2016 Open Access This article is distributed under the terms of the Creative Commons Attribution 4.0 International License (http://creativecommons.org/licenses/by/4.0/), which permits unrestricted use, distribution, and reproduction in any medium, provided you give appropriate credit to the original author(s) and the source, provide a link to the Creative Commons license, and indicate if changes were made. The Creative Commons Public Domain Dedication waiver (http://creativecommons.org/publicdomain/zero/1.0/) applies to the data made available in this article, unless otherwise stated. 


\section{Background}

The grapevine cultivated in Europe (Vitis vinifera) is subject to diseases due to many bioagressors, notably obligate fungal and oomycete parasites such as powdery mildew (Erysiphe necator) and downy mildew (Plasmopara viticola). Control of epidemics requires numerous chemical treatments with harmful effects on the environment and human health. In addition to plant breeding and biological control, the use of plant defense stimulators (elicitors) could be a promising alternative.

Usually acting on the plant and not directly on the pathogen, elicitors induce a multi-factorial plant resistance which is probably more difficult to overcome by the pathogen than protection provided by an single-site fungicide [1]. There are a wide variety of abiotic or biotic elicitors of animal, plant, fungal or bacterial origin [2]. In recent years, considerable progresses have been made to identify the mode of action of elicitors on various plant models and to identify the genes involved in defense responses [3]. The induced immunity activates a wide variety of defense mechanisms that involve passive defense mechanisms [4] that restrict the entry or spread of the pathogen in the plant, but also active defense mechanisms that prevent the development of the pathogen by confining it to the site of infection or causing its death. The most common early cellular responses are mechanisms of ion flux changes, production of reactive oxygen species (ROS) and phosphorylation mechanisms/ dephosphorylation (mitogen -activated protein kinase or MAPKKK, MAPKK and MAPK [5-7]. After these early steps, some secondary metabolic pathways are stimulated and allow the generalization of the response to the whole plant, while systemic acquired resistance (SAR) is being established $[8,9]$. SAR requires systemic movement of signals from the infected tissue to healthy tissue. Molecules such as salicylic acid (SA), jasmonic acid (JA), ethylene (ET), systemin and even hydrogen peroxide, which are involved in the different signaling pathways, are activated in response to elicitation [10-13]. They rapidly accumulate in the cell and allow the defense genes to be expressed. Regulating defenses by SA, JA/ET is complex and to date these signaling pathways have appeared to interact with each other $[14,15]$. Following the defense reaction, the intracellular signaling pathways in plants converge towards the production of active forms of oxygen and hormones (SA, JA, ET or ABA). Final steps correspond to the induction of defense genes, the production of secondary metabolites (phytoalexins, PR-proteins) and the strengthening of cell walls, which all contribute to stopping the development of the pathogen $[2,3,5]$. However, despite considerable progress in understanding the activity of elicitors and their reproducible effects in controlled laboratory conditions, their application in natura on crops such as grapevine has been rather disappointing [2].
In view of this situation, greater insight is needed into grapevine immune responses in relation to the genetic background of the plant, pathogen diversity and environmental conditions. Preliminary studies in our laboratory allowed us to select potential elicitors with a defined chemical composition, and which have stable reproducible efficiency under controlled conditions against the two major pathogens of grape: powdery mildew (Erysiphe necator) and downy mildew (Plasmopara viticola). We focused particularly on phosphonates and benzothiadiazole (BTH or acibenzolar-S-methyl (ASM)), which are already known as stimulators of plant defenses [16-23]. BTH has been shown to be effective against a broad spectrum of pathogens in various plants [19-30], with no direct antifungal activity, thereby clearly establishing its role as an inducer that is dependent on the salicylic acid (SA) pathway [31]. According to its mode of action, BTH is classified by FRAC (Fungicide Resistance Action Committee, http://www.frac.info/) in P1 group, no reporting any resistance phenomenon until now. Fosetyl-aluminum (FOS, [aluminum tris (ethyl phosphonate)]), is a phosphonate used against diseases caused by oomycetes [32]. The mode of action of FOS is multi-site which avoids resistance phenomenons, being classified by FRAC in 33 group. It is remarkable that according to FRAC, few resistance cases have been reported in few pathogens after more than 30 years of utilization. It has a complex mode of action with a direct effect on pathogens at high doses as well as an indirect activity thanks to enhanced plant defense responses at low doses [33]. Phosphonates have been widely studied for their role as phytoalexin inducer [33-37].

To monitor the activity of these compounds in the field, it is possible to assess their defense inducer effect by analyzing the expression of a significant number of marker genes involved in the defense process of grapevine. Recently, two molecular diagnostic tools were designed that provide information about the defense status of grapevine: "qPFD” (quantitative RT-PCR microplate/ DNA chip low density) which was first developed on the apple scab model (Malus domestica/Venturia inaequalis) and extended to grapevine and evaluates a set of nine groups representing 28 target genes (patent INRA WO 2011/161388, CT/FR2011/051470 - INRA Angers - Brisset MN) [38]; and "BioMolChem"chip which is based on 20 marker genes highly involved in grapevine defense mechanisms [26]. However, a more accurate diagnostic tool would certainly require a larger number of defense markers since genomic analyses have shown that induction of the plant immune system is linked to changes in the expression of thousands of genes [39]. Recently, considerable progress has been made in the development of automated platforms that enable the high-throughput analysis of gene expression by Q-PCR [40], notably involving microfluidic chips. 
Here, we describe the construction of a new "NeoVigen96" chip allowing the detection of 85 defense markers and 11 genes used for standardization of expression (constitutively expressed genes) on 95 cDNA preparations in a single run. The chip was used to study the inducer activity of BTH and FOS in leaves collected in the field.

The general idea of this work is not to demonstrate that these BTH and FOS applications should be used as they are performed in this article in the context of conventional programs to protect the grapevine, but to demonstrate that it is possible to test the effects of potential elicitor products on grapevine defense responses with the Fluidigm tool. The resulting data provide better understanding of grapevine defense status with a view to optimizing the potential of plant defense elicitors.

\section{Results and discussion}

\section{"NeoViGen 96" chip conception and validation}

Induction of plant immunity implements molecular signaling cascades that ultimately lead to different levels of mechanical and chemical protection. Typically, this inducible resistance system is controlled by phytohormones such as salicylic acid (SA) [8], jasmonic acid and ethylene, leading to the coordinated accumulation of pathogenesisrelated proteins (PR proteins), the production of phytoalexins and the reinforcement of plant cell walls [3].

We used various strategies in order to obtain the most recent molecular data and find homologs to the already known responsive gene sequences and find new targets. An additional file shows the origin of the sequences and/or references used to find new candidate genes involved in grapevine defenses (Additional file 1). The strategy combines two approaches : the first was based on the comparison of new grapevine genomic data with known grapevine sequences previously selected from pathogen-related studies to which were added genes deployed in two recently developed molecular diagnostic tools ("grapevine - qPFD", patent INRA FR 1055042/ WO/2011/161388, CT/FR2011/051470 - INRA Angers Brisset MN, [38] and "BioMolChem" chip, [26]). The sequences used in RT-qPCR were blasted against the most recent Vitis vinifera sequences (taxid $=29,760$, [41]) using the Blast resource from the National Center for Biotechnology Information (https://blast.ncbi.nlm.nih.gov/Blast.cgi). Nucleotide sequences were used and results were manually curated to find homologs to the original sequences used in the RT-qPCR experiments. Homology was confirmed by aligning selected sequences with Clustal [42] and generating phylogenetic trees. Once recovered, the sequences to be included in the Fluidigm protocol were subjected to the primer-blast program [43] for specific primer design.

The second strategy combined with the first involved the recovery of sequences from the model organism $A$. thaliana in the Genevestigator database [44]. Microarray experiments involving foliar fungal pathogens deposited in Genevestigator were selected and the most differentially expressed plant sequences between control and treated samples were recovered. These sequences $(N=273)$ were identified on the NCBI website and aligned against the most recent Vitis vinifera sequences using the NCBI Blast resource. The mean percentage of Vitis vinifera protein sequence homology/ortology with those of Arabidopsis thaliana and/or Malus domestica was 53\%, between 16 and 99 (Additional file 2).

The combination of the two strategies gave rise to 96 new Vitis sequences included in the Fluidigm protocol (Tables 1 and 2). The gene set included reference genes $(N=11)$, PR proteins $(N=28)$, some genes involved in secondary metabolites (phenylpropanoids, $N=15$ ) and indole pathway $(N=5)$, others involved in the oxidoreduction system $(N=5)$, in the ethylene or oxylipine/JA pathways $(N=4)$, cell wall reinforcement $(N=13)$ and others involved in pathogen detection-signaling and transcription signaling $(N=15$; Fig. 1$)$.

We verified that the qPCR was specific for each primer set (appropriate specific target) by checking the appropriate size of the amplified product on agarose gel (not shown) and obtained a single peak in the melting curve after each qPCR run. We also checked that the PCR efficiencies for each primer set were similar (0.8-1.2), thereby allowing us to simplify Pfaffl's model formula for calculating relative expression [45] with $2^{-\Delta \Delta C q}$ (data not shown).

\section{Method sensitivities}

The Cq values obtained on a subset of 23 genes were compared for the same samples in two real-time PCR systems: the Stratagene Mx3005P and the Biomark HD, a Fluidigm ${ }^{\odot}$ integrated fluidic circuits (IFCs) by automating PCR reactions in nanoliter volumes [46]. Twenty-two out of 23 mRNAs exhibited lower Cq values in the Fluidigm dynamic array than those obtained with the Stratagene MX3005P (15.60 \pm 0.42 for the 96.96 dynamic array and $19.54 \pm 0.42$ for the Stratagene, mean difference, $3.96 \pm 0.17$ ), suggesting that the microfluidic technology exhibited a greater sensitivity than the Stratagene while the amounts of cDNA used in this technique were 70-150 times lower (Fig. 2a, b and c).

\section{Comparison of mRNA expression between 96.96 dynamic array and Stratagene Mx3005P}

Eleven genes were selected to test the stability of their expression in all of the samples studied (control and treated, Table 2) so as to identify constitutive markers that could be used to normalize qPCR results. Multiplegene normalization was based on the principles and formulas described by Vandesompele [47]. Genes were considered 
Table 1 Genes used in "BioMolChem" chip that were analyzed in the Stratagene Mx3005P qPCR system, classified according to functions and pathways

\begin{tabular}{|c|c|c|c|c|c|}
\hline & Defense-related genes & Names & $\begin{array}{l}N^{\circ} \text { accession } \\
\text { GeneBank }\end{array}$ & Forward primer $\left(5^{\prime}-3^{\prime}\right)$ & Reverse primer $\left(5^{\prime}-3^{\prime}\right)$ \\
\hline Reference gene & $\gamma$-chain of Elongation Factor 1 & EFIY & AF176496 & GAAGGTTGACCTCTCGGATG & AGAGCCTCTCCCTCAAAAGG \\
\hline \multirow[t]{7}{*}{$P R$ proteins } & PR1 Unknown function & PR1 & AJ536326 & CCCAGAACTCTCCACAGGAC & GCAGCTACAGTGTCGTTCCA \\
\hline & Beta-1,3-glucanase (PR2) & GLU & AF239617 & GGGGAGATGTGAGGGGTTAT & TGCAGTGAACAAAGCGTAGG \\
\hline & Endochitinase (Chitinase IV - PR3) & CHIT4a & U97521.1 & TATCCATGTGTCTCCGGTCA & TGAATCCAATGCTGTTTCCA \\
\hline & proteinase inhibitor (PR6) & PIN & XM_002284418 & ACGAAAACGGCATCGTAATC & TCTTACTGGGGCACCATTTC \\
\hline & Chitinase III - (PR8) & CHIT3 & Z68123 & AATGATGCCCAAAACGTAGC & ATAAGGCTCGAGCAAGGTCA \\
\hline & PR protein - class 10 (PR10) & PR10 & AJ291705 & GCTCAAAGTGGTGGCTTCTC & CTCTACATCGCCCTTGGTGT \\
\hline & $\begin{array}{l}\text { Polygalacturonase Inhibiting } \\
\text { Protein }\end{array}$ & $P G I P$ & XM_002263487.1 & GAGCGATGCCACCCCAGTGA & CCGTTGAGTCGGACGCTCGAC \\
\hline \multirow{6}{*}{$\begin{array}{l}\text { Phenylpropanoid } \\
\text { pathways }\end{array}$} & Phenylalanine ammonia lyase & PAL & X75967 & ACAACAATGGACTGCCATCA & CACTTTCGACATGGTTGGTG \\
\hline & Stilbene synthase & STS & X76892.1 & ATCGAAGATCACCCACCTTG & CTTAGCGGTTCGAAGGACAG \\
\hline & Chalcone Synthase & CHS & X75969.1 & CCAACAATGGTGTCAGTTGC & CTCGGTCATGTGCTCACTGT \\
\hline & Chalcone Isomerase & $\mathrm{CHI}$ & X75963 & AGAAGCCAAAGCCATTGAGA & CCAAGGGGAGAATGAGTGAA \\
\hline & Anthocyanidine synthase & LDOX & X75966 & TGGTGGGATGGAAGAGCTAC & CCCACTTGCCCTCATAGAAA \\
\hline & Flavanone-3-hydroxylase & $\mathrm{F} 3 \mathrm{H}$ & X75965.1 & TGACTCGCTCTCTTCAAGCA & CACCTTGGGACGTTCATCTT \\
\hline \multirow[t]{3}{*}{ Indole pathways } & Antranilate Synthase & ANTS & XM 002281597 & AAAAATCCAAGAGGGGTGCT & AAGCTTCTCCGATGCACTGT \\
\hline & Chorismate mutase & CHORM & FJ604854 & TCATTGAGAGGGCCAAATTC & AGGAGGCAGAAAAAGCATCA \\
\hline & Chorismate Synthase & CHORS & FJ604855 & GCCTTCACATGCAGATGCTA & CTGCAACTCTCCCAATGGTT \\
\hline Redox status & Glutathione S-transferase & GST1 & AY156048.1 & GGGATCTCAAAGGCAAAACA & AAAAGGGCTTGCGGAGTAAT \\
\hline Lipoxygenases & Lipoxygenase-9 & LOX9 & AY159556 & GACAAGAAGGACGAGCCTTG & CATAAGGGTACTGCCCGAAA \\
\hline Signaling & $\begin{array}{l}\text { 1-aminocyclopropane, 1-carboxylic } \\
\text { oxidase }\end{array}$ & $A C C$ & AF424611 & GAAGGCCTIITACGGGTCTC & CCAGCATCAGTGTGTGCTCT \\
\hline \multirow{3}{*}{$\begin{array}{l}\text { Cell Wall } \\
\text { Reinforcement }\end{array}$} & Glycosyl transferase & CAGT & XM02273320.1 & TCGGAAGGGAATGCAATAAG & TGTAGGAGGAACCACCCTTG \\
\hline & Callose Synthase & $C A L S$ & AJ430780.1 & TGGAAATGCAATTCAAACGA & CGAATGCCATGTCTGTATGG \\
\hline & Lignin-forming peroxidase & PER & XM_002274762.1 & TAAGCGCCACAAGAACACTG & GGACCTCCTTGTTGAGTCCA \\
\hline
\end{tabular}

as stable when their $M$ values were less than 1.5 (Fig. 3). In our study, all selected genes were considered stable ( $\mathrm{M}$ mean value $=0.73 \pm 0.25$, Fig. 3 ) and multiple-gene normalization was performed with the geometric mean of all reference genes as an accurate normalization factor. The most stable genes in the samples studied were THIORYL58, TuA, TIP41, GAPDH and EF1Y (Fig. 3) with $M$ values between 0.46 and $0.68(0.52 \pm 0.04)$. The optimal number of genes required for normalization of RT-PCR data was fixed with these 5 genes for subsequent experiments with a second "NeoVigen 96" chip version.

We compared fold-change expression of defense-related gene in the same samples measured by the 96.96 dynamic array with those obtained from the "BioMolChem" chip with the Stratagene Mx3005P (Fig. 4). Fold change comparisons were similar between the two platforms, which indicated a perfect significant correlation between the two technologies $\left(R^{2}=0.737\right.$ and Pearson's correlation $($ PPMCC $)=0.86 ; p$-value $<0.05)$. The maximum fold change detected by the Stratagene was 2.59 compared to 2.28 by the 96.96 dynamic array (Fig. 4).

\section{Grapevine protection induced by BTH and FOS treatments}

The effect of BTH and FOS on downy mildew was evaluated. The mode of action of BTH is only through stimulation of plant defenses [17, 27], while that of FOS is more complex with direct and indirect effects [9]. Previous studies showed that this complex mode depends on the dose applied by soil drenching [33], with an indirect effect at low dose $(<10 \mathrm{mM})$ and a direct effect at high dose $(>50 \mathrm{mM})$. In our study, FOS was applied on grapevine foliage at the authorized dose $\left(2.5 \mathrm{kG} \mathrm{Ha}^{-1}\right.$ corresponding to $7.05 \mathrm{mM}$ ) for which a direct action has already been shown leading to an inhibition of $87.5 \%$ of downy mildew spores germination at a dose 5 times lower $(1.13 \mathrm{mM})$ [27]. Figure 5 shows that treatment of grapevine leaves with BTH and FOS in field conditions led to a significant reduction in downy mildew symptoms compared to untreated control leaves, with a better efficiency of FOS. The severity of grapevine downy mildew (Plasmopara viticola) in FOS and BTH-treated blocks at the end of 28 th July were 85 and $70 \%$ lower than on 
Table 2 Genes used in "NeoVigen96" chip that were analyzed in the Biomark HD system, classified according to functions and pathways

\begin{tabular}{|c|c|c|c|c|c|c|}
\hline Gene Functions & & $\begin{array}{l}\text { Gene } \\
\text { Names }\end{array}$ & $N^{\circ}$ accession & Primer Sens $-5^{\prime}>3^{\prime}(F)$ & Primer AntiSens - 5' > 3' (R) & $\begin{array}{l}\text { PCR } \\
\text { efficacies }\end{array}$ \\
\hline \multirow[t]{11}{*}{ Reference genes } & Elongation factor 1 chain $\gamma$ & $E F 1 \gamma^{a}$ & AF176496 & GAAGGTTGACCTCTCGGATG & AGAGCCTCTCCCTCAAAAGG & 1.09 \\
\hline & $\begin{array}{l}\text { Serine/threonine-protein phosphatase } \\
2 \mathrm{~A}\end{array}$ & $P P 2 A$ & XM_002276144 & TCCGGCGGCTCTCGACGATT & TTCGCGTGCTCAACACCTCCG & 0.97 \\
\hline & SAND family protein (endocytosis) & SAND & XM_002285134 & GCCCCACAGCCAAACCCCTC & ACGATCCGTTTGCGACCCCG & 1.05 \\
\hline & $\begin{array}{l}\text { Pentatricopeptide repeat-containing } \\
\text { protein }\end{array}$ & Unknown & XM_002274855 & TGGTGAACTTGAGGCTGCAAGGG & ACCATTTGGGGAGTAGCCCTTCCTC & 1.01 \\
\hline & Ubiquitin Conjugating Enzyme 9 & UBC9 & XM_002274238 & TCCTCCTGACAGTCCATATGCTGGT & GGGCTGGGCTCCACTGCTCC & 1.00 \\
\hline & TIP41-like protein & TIP41 & XM_002270674 & CAGCGGGCAGCGATCGAAGA & CATTTCCGCTCCGGCAGCCTT & 1.05 \\
\hline & Catalytic thioredoxin-like protein $4 \mathrm{~A}$ & THIORYLS8 & XM_002283586 & TCACTCTGGATGGGCCGTCG & TCCCAATCGTGGCCGAACCG & 1.14 \\
\hline & Tubulin alpha & TuA & XM_002285685.1 & GTCGGCGCTGAAGGTGTGGA & GAGGTGGCGGGCAAACCCTC & 0.97 \\
\hline & \multirow[t]{2}{*}{ Tubulin beta } & $\beta$ Tub & XM_002275270.1 & TGAACCACTTGATCTCTGCGACTA & CAGCTTGCGGAGGTCTGAGT & 0.99 \\
\hline & & TuB & XM_02275270.1 & CGCCACCCGAGTCTCACTGC & CACACCGTGCTCGTCGCAGA & 1.04 \\
\hline & $\begin{array}{l}\text { Glyceraldehyde 3-phosphate } \\
\text { dehydrogenase }\end{array}$ & GADPH & XM_002263109.1 & GAAATCAACGGCCCAGCGCG & CCGGTGGATACTGGGGCGGA & 0.83 \\
\hline \multirow[t]{19}{*}{ PR protein } & \multirow[t]{2}{*}{ PR1 Unknown function } & $P R 1^{\mathrm{a}}$ & AJ536326 & CCCAGAACTCTCCACAGGAC & GCAGCTACAGTGTCGTTCCA & 1.00 \\
\hline & & PR1 bis & XM_002273752.1 & GGGGTTGTGTAGGAGTCCATTAGCA & TGGGCACAGCAGATGTGAGCT & 1.13 \\
\hline & \multirow[t]{2}{*}{ Beta-1,3-glucanase } & $G L U^{a}$ & AF239617 & GGGGAGATGTGAGGGGTTAT & TGCAGTGAACAAAGCGTAGG & 1.18 \\
\hline & & $P R 2$ & XM_002277475 & CAACTTGCCACCGCCAGGGC & AGGGCTTGGAGAGCAGCTTGG & 0.96 \\
\hline & \multirow{2}{*}{$\begin{array}{l}\text { Endochitinase (Chitinase type I, II, IV }{ }^{\prime} \mathrm{VI} \\
\text { and VII) }\end{array}$} & PR3 & U97522.1 & ACTACGGCGCTGCTGGAAACA & TGGCACCGAAACCTTGGCTTAG & 1.16 \\
\hline & & CHIT $4 a^{a}$ & U97521.1 & TATCCATGTGTCTCCGGTCA & TGAATCCAATGCTGTTTCCA & 1.14 \\
\hline & \multirow[t]{2}{*}{ Chitin binding Chitinases type I, II } & PR4 & XM_002264684.1 & CCCAGAGCGCCAGCAATGTGA & TTGCTGCGCCATGCCAAGGG & 0.95 \\
\hline & & PR4bis & XM_002264611.1 & TGGCTACTGCGGAACAACGGC & CAAGTGGCGCAGTAGGCGCT & 1.02 \\
\hline & \multirow[t]{2}{*}{ Thaumatin-like/Osmotin } & PR5 & XM_002282928.1 & GGAGGCAATGGTTTCCACCTTGGG & ACTTGGACGGGACCATAGAGGTTAG & 0.99 \\
\hline & & PR5bis & XM_002282874.1 & CCCCGGCACCACCAATGCTC & TGGGGGAGAACCGTAGCCCTG & 1.18 \\
\hline & \multirow[t]{3}{*}{ Proteinase inhibitor } & $P I N^{a}$ & XM_002284418 & ACGAAAACGGCATCGTAATC & TCTTACTGGGGCACCATTTC & 1.23 \\
\hline & & PR6 & XM_002277772 & TGGGAAGCAGGCTTGGCCTGA & ACCTGGCTCTCACCGAAGGG & 0.99 \\
\hline & & PR6bis & XM_002280597.1 & GCCAGAGCTGGTGGGCGTAC & AGGCGCCATACTCACGATGCC & 1.10 \\
\hline & \multirow[t]{2}{*}{ Subtilisin-like endoprotease } & $P R 7$ & XM_002275435.2 & TGCTCCCAATCATGGTGGCTGT & TGAAGACTCTGCGGTGTGTCCT & 1.01 \\
\hline & & $P R 7$ bis & XM_002275435.1 & CGTTAAGCAGCTGGAAAGGAGCA & TCCTCCGTCAGTCTGGCTGCAA & 1.04 \\
\hline & \multirow[t]{2}{*}{ Chitinase type III } & CHIT $^{\mathrm{a}}$ & Z68123 & AATGATGCCCAAAACGTAGC & ATAAGGCTCGAGCAAGGTCA & 0.98 \\
\hline & & PR8 & XM_002276329 & GCAACAAAGCTCAATGGCACACCAC & CAGCCAAGCTGCCCTCGTTCC & 0.96 \\
\hline & \multirow[t]{2}{*}{ Lignin-forming peroxidase } & $P O X^{a}$ & XM_002285687.1 & ACTGCACCAAGAAAGAGCACCAG & AGCTGTGCATGTGCCATCCCC & 1.14 \\
\hline & & $P R 9-b$ & XM_002285613.1 & AGCGAGCGAGAAAGACGCGA & GAGACGACGCCTGGGCAGAC & 0.91 \\
\hline
\end{tabular}


Table 2 Genes used in "NeoVigen96" chip that were analyzed in the Biomark HD system, classified according to functions and pathways (Continued)

\begin{tabular}{|c|c|c|c|c|c|c|}
\hline & Ribonuclease-like & $P R 10^{a}$ & AJ291705 & GCTCAAAGTGGTGGCTTCTC & CTCTACATCGCCCTTGGTGT & 0.99 \\
\hline & Chitinase type I & $P R 11$ & XM_002270543.1 & CTCCACTGCGCAAACCGTGGT & TTTGCGTTTCGGAGGAAATCGTGA & 1.10 \\
\hline & Defensin & $P R 12$ & XM_002281153 & GTGCAAGAACTGGGAGGGTGCC & GCAGAAGCATGCAACTCCCGGG & 0.88 \\
\hline & Lipid Transfer Protein & PR14 & XM_002271080 & ACAGTTGATCGCCAGGCCGC & GCCCGGAAGCCCACTTGCAA & 1.18 \\
\hline & & PR 14bis & XM_002270934 & CGCCACCACACAAGACCGCA & AGGGAGGCCAGCAGCCAGAC & 1.01 \\
\hline & Germin-like Protein- Oxalate oxidase & PR15 & & GTTCCTGGCCCTCATGGAATTGGC & GTGTCCTGCAGTGGGCTTGGA & 1.19 \\
\hline & & PR15bis & XM_002284176.1 & GCCATGGCAGATGATTTCTT & TGCAATTTGGGCAACATTTA & 0.87 \\
\hline & Polygalacturonase Inhibiting Protein & $P G / P^{a}$ & XM_002263487.1 & GAGCGATGCCACCCCAGTGA & CCGTTGAGTCGGACGCTCGAC & 0.96 \\
\hline \multirow{18}{*}{$\begin{array}{l}\text { Secondary metabolites } \\
\text { biosynthesis }\end{array}$} & Phenylalanine ammonialyase & $P A L^{\mathrm{a}}$ & X75967 & ACAACAATGGACTGCCATCA & CACTTTCGACATGGTTGGTG & 1.10 \\
\hline & Stilbene synthase (resveratrol synthase) & $S T S^{\mathrm{a}}$ & X76892.1 & ATCGAAGATCACCCACCTTG & CTTAGCGGTTCGAAGGACAG & 0.95 \\
\hline & Resveratrol O-methyl-transferases & ROMT & FM178870 & TGCCTCTAGGCTCCTTCTAA & TTTGAAACCAAGCACTCAGA & 0.96 \\
\hline & & ROMT2 & XM_002281445.1 & TCCACACTGCTTACGAGCGGT & CAACCCCGCAAATACGCCCTGG & 0.99 \\
\hline & Chalcone Synthase & $\mathrm{CHS}^{\mathrm{a}}$ & X75969.1 & CCAACAATGGTGTCAGTTGC & CTCGGTCATGTGCTCACTGT & 1.01 \\
\hline & & CHS2 & XM_002276885.1 & GCATTITCCGACGAAGTTCACACTG & GTGCCGATGGCCAGAACCGT & 1.04 \\
\hline & Chalcone Isomerase & $\mathrm{CH}^{\mathrm{a}}$ & X75963 & AGAAGCCAAAGCCATTGAGA & CCAAGGGGAGAATGAGTGAA & 1.04 \\
\hline & & $\mathrm{CH} 2$ & XM_002280122 & TGTGGGCCATCTGCAACCATGG & GCACTCTCTAGCTGCACCCCG & 1.12 \\
\hline & Dihydro Flavonol Reductase & $D F R$ & XM_002281822.1 & GGCCACCGTTCGCGATCCAA & GAAGACGCCGGTGCAGCCTT & 1.05 \\
\hline & Anthocyanidine synthase & $\angle D O X^{a}$ & X75966 & TGGTGGGATGGAAGAGCTAC & CCCACTTGCCCTCATAGAAA & 0.84 \\
\hline & Polyphenol Oxidase & $P P O$ & XM_002275806.1 & GGTCCCTCGTTATGGGGCCGA & CCTGGATGGAAATCAGGGCGCC & 0.98 \\
\hline & $\begin{array}{l}\text { 3-hydroxy-3-methylglutaryl Coenzyme A } \\
\text { reductase }\end{array}$ & $H M G R$ & XM_002275791.1 & AACGCACACTCCGCTCCACG & GCGGCGGCGATCTTCATCGA & 0.93 \\
\hline & Farnesyl Pyrophosphate Synthase & FPPS & XM_002272605.1 & TCGCCAATGGGTCGAGCGTA & TGCCTGCCTTGCAGCAACTTGT & 1.03 \\
\hline & $(E, E)$-alpha-farnesene synthase & FAR & XM_002281343.1 & GCCATGGCACTCCACCTCTCCTAA & AGGCGGGCTGGTAATGCGCT & 0.99 \\
\hline & & FAR2 & XM_002264969.1 & TTGCGAGGCAGAAGCTGGCC & TाTGGCCCACGAAAGGCGGG & 1.08 \\
\hline & Flavanone-3-hydroxylase & $F 3 H^{a}$ & X75965.1 & TGACTCGCTCTCTTCAAGCA & CACCTTGGGACGTTCATCTT & 0.87 \\
\hline & & $\mathrm{F} 3 \mathrm{H}$ bis & $X M \_002275553.1$ & TCCAGCCCGTGGAAGGAGCA & TGCTCAGATACTGCCCACCCAA & 0.96 \\
\hline & Carboxylesterase & HSR-203 J & XM_002285050.1 & TGGAGGAAACATCGTTCACA & CCTGGACAATTCTGCCATCT & 1.02 \\
\hline \multirow[t]{5}{*}{ Indole biosynthesis } & Antranilate Synthase & ANTS $^{a}$ & XM 002281597 & AAAAATCCAAGAGGGGTGCT & AAGCTTCTCCGATGCACTGT & 0.84 \\
\hline & Chorismate mutase & CHORM ${ }^{\mathrm{a}}$ & FJ604854 & TCATTGAGAGGGCCAAATTC & AGGAGGCAGAAAAAGCATCA & 1.05 \\
\hline & & CHORM2 & XM_002284083.1 & GGCAAGTTCGTGGCAGAGGCA & GCCGCTGGCTGTCTTGTGCT & 1.11 \\
\hline & Chorismate Synthase & $\mathrm{CHORS}^{\mathrm{a}}$ & FJ604855 & GCCTTCACATGCAGATGCTA & CTGCAACTCTCCCAATGGTT & 1.00 \\
\hline & & CHORS2 & XM_002282263 & TGTTATGGCGCGCGGTGACT & GCAGCTCTGGCCAGTTGAGCT & 1.11 \\
\hline
\end{tabular}


Table 2 Genes used in "NeoVigen96" chip that were analyzed in the Biomark HD system, classified according to functions and pathways (Continued)

\begin{tabular}{|c|c|c|c|c|c|c|}
\hline \multirow[t]{5}{*}{ 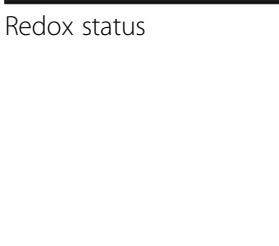 } & \multirow[t]{5}{*}{ Glutathione S-transferase } & GST $^{\mathrm{a}}$ & AY156048.1 & GGGATCTCAAAGGCAAAACA & AAAAGGGCTTGCGGAGTAAT & 0.99 \\
\hline & & GST2 & AY156049 & CATGAAGGCCGGCCAGCACA & CGCGAAGAATTCGCTCTGGCCA & 0.84 \\
\hline & & GST3 & XM_002283178 & TGTTTGGCCGCAAACGGGGT & TCCCCAGCCAGGTACTTGCTCT & 1.06 \\
\hline & & GST4 & XM_002271673 & AGCTGGAATGGCGCACTTGGT & TGGAAAGGTGCATACATGGCCACG & 1.00 \\
\hline & & GST5 & XM_002283173 & CCTTGAGCTCTACCCTGCCCCA & AGCAGCCAGCCCTAGACATGGA & 0.86 \\
\hline \multirow[t]{4}{*}{ Oxylipines } & \multirow[t]{3}{*}{ Lipoxygenase 13} & LOX2 & XM_002285538 & AAACCGTGCATTCCCGGCCC & GGCAGGGACGTAGCCAACCC & 1.02 \\
\hline & & LOX3 & XM_002284499.2 & GGACCGGGTTCATGAGCTGTTGG & TGAATGCAGACTCGCCAGCGGT & 1.09 \\
\hline & & LOX4 & XM_002280615.1 & CCACAAGCGAAGGCGGGCTT & AGCAATGTGCATTTCAGCCATCGA & 1.10 \\
\hline & Lipoxygenase 9 & $\angle O X 9^{\mathrm{a}}$ & AY159556 & GACAAGAAGGACGAGCCTTG & CATAAGGGTACTGCCCGAAA & 0.92 \\
\hline \multirow[t]{14}{*}{ Cell wall reinforcement } & \multirow[t]{2}{*}{ Alliinase } & Alli & XM_002265837.1 & CGGCTCAGCCTCATCAAGACCC & GGCATGCATGTCATCTTCCTCAGCC & 1.04 \\
\hline & & Alli2 & XM_002266017.1 & AGCCCTTCTGGATGCAGCATGC & TGTAGCTTGCGGATGAGCTTCACT & 1.00 \\
\hline & \multirow[t]{2}{*}{ Ascorbate peroxidase } & APOX & XM_002284731.1 & AGCTCAGAGGCCTCATCGCTGA & TACCGGCAGAGTGCCATGCG & 1.07 \\
\hline & & APOX2 & XM_002278245.1 & TCGAAGCTCAGCAGACGCCG & ACGTCCCCGCATCATGCCAC & 1.14 \\
\hline & \multirow{2}{*}{$\begin{array}{l}\text { Glycosyl transferase (Coniferyl alcohol } \\
\text { glucosyl transferase) }\end{array}$} & $C A G T^{a}$ & XM02273320.2 & TCGGAAGGGAATGCAATAAG & TGTAGGAGGAACCACCCTTG & 0.81 \\
\hline & & CAGT2 & XM_002276999.1 & TGTTCATGAGGGCTGCGCCG & CACCAGGCAGCTCACTGGCC & 1.00 \\
\hline & \multirow[t]{3}{*}{ Callose Synthase } & $C A L S^{\mathrm{a}}$ & AJ430780.1 & TGGAAATGCAATTCAAACGA & CGAATGCCATGTCTGTATGG & 0.86 \\
\hline & & CALS2 & XM_002283262 (CS-like 12) & ATGGCGTCCAGAAGCGGCTC & GCCGTCTGTGTCCGCGTGAT & 0.86 \\
\hline & & $C A L S 3$ & $\begin{array}{l}\text { XM_002285608.1 (CS-like- } \\
\text { 10) }\end{array}$ & GCAGCAGATTGCCACTGCCCA & AGGCAGAATGAGGTGCTCGCC & 1.14 \\
\hline & Lignin-forming peroxidase & $P E R^{\mathrm{a}}$ & XM_002274762.1 & TAAGCGCCACAAGAACACTG & GGACCTCCTTGTTGAGTCCA & 0.93 \\
\hline & \multirow[t]{2}{*}{ Pectin methyl esterase } & PECT1 & XM_002275783.2 & TGTTGGCCTCGAGGAGAGGGG & GGGAGGCCTACAGACCAAAAGTCA & 1.18 \\
\hline & & PECT2 & XM_002283905.1 & GGGTTGCGCCCTGAGGACAC & CAATCACCCGAGCCGCCTGG & 1.08 \\
\hline & \multirow[t]{2}{*}{ CAD Cinnamyl alcohol dehydrogenase } & $C A D$ & XM_002285332.1 & AGTCCGATTGGAAGACGGCAGT & TGCCCCTGTCACACACACCA & 1.05 \\
\hline & & CAD2 & XM_002268086.1 & TCCGGGTATCCCAGGAGAAAGCA & TCCACGGTATCCTTCATGCTCACC & 1.07 \\
\hline \multirow[t]{10}{*}{ Signaling } & SA Methyl Transferase & SAMT1 & XM_002262982.1 & AATCCTTGCCCAAGTTCCAG & GAGACAACCATTGGAGACTG & 1.16 \\
\hline & Allene Oxide Synthase & AOS1 & XM_002281190.1 & TTATGGCTTGCCCTTCTTTGG & ATGGAGTCGAGGAGGACGAT & 0.94 \\
\hline & \multirow[t]{3}{*}{ Lipase 3/enhanced disease susceptibility 1} & EDS1a & XM_002281059.1 & CAGGTCACAGCCTGGGTGCG & TCGGGCGGGACGATCTCGTT & 1.01 \\
\hline & & EDS1b & XM_002281871.1 & GGAGACGGGGCTGAACGTGC & CCATCGCCGGCACTTGCTCA & 0.89 \\
\hline & & EDS1C & XM_002275822.1 & CCAGCACTGCTTGCAGGCGT & TGCTGTGTTCCTGAGTGCCCC & 1.04 \\
\hline & \multirow[t]{2}{*}{ Transcription Factors } & WRKY1 & AY585679.1 & GGAAATATGGGCAGAAAGCA & ATCTITGAGAGGCGTTGGA & 1.00 \\
\hline & & WRKY2 & AY596466 & AGAGGCAAGGCGATGTAGAA & CTGGGGAACAAGCCTTCATA & 1.01 \\
\hline & \multirow[t]{3}{*}{$\mathrm{JAR}=$ Jasmonate-resistant 1} & $J A R$ & XM_002283193.1 & GCAACGGGGCACGACTACTGT & GCCGTGGCGGTGCAAGTACT & 0.89 \\
\hline & & JAR2 & XM_002280702.1 & CCGAAGTGCTGGCCCCAGAG & AACGCTCACTTCGCCGCTGA & 1.00 \\
\hline & & JAR3 & XM_002268242.1 & GGAGCAATGCTGCTCCACAGTGG & GGCGTCGAATGTGCCAGGCT & 1.01 \\
\hline
\end{tabular}


Table 2 Genes used in "NeoVigen96" chip that were analyzed in the Biomark HD system, classified according to functions and pathways (Continued)

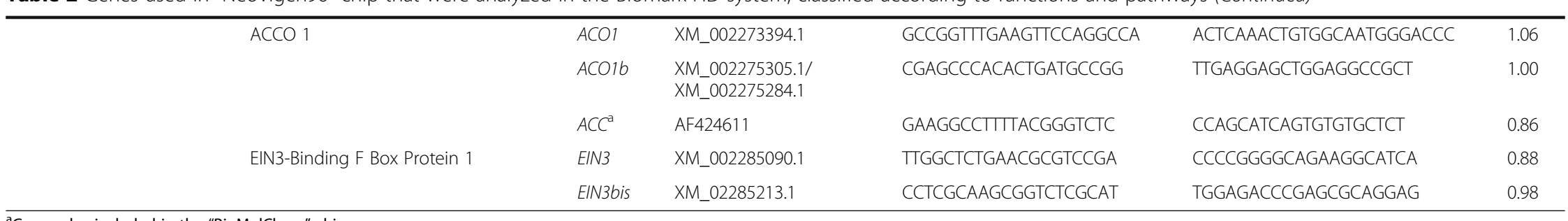




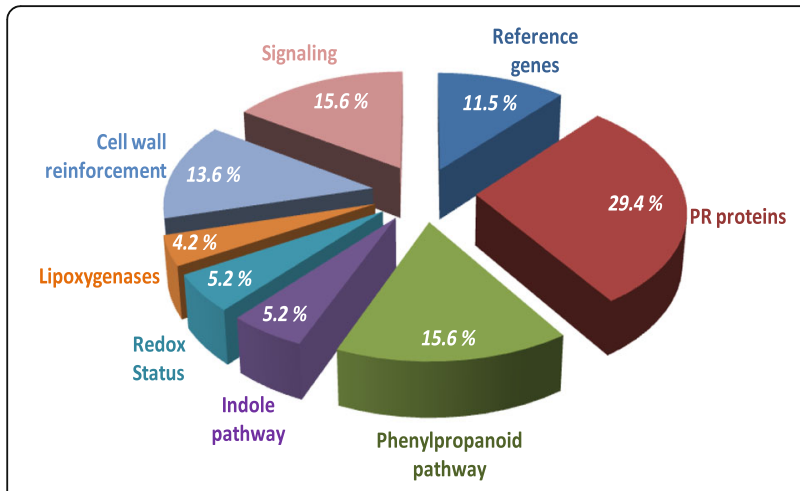

Fig. 1 Function of genes analyzed using the "NeoViGen96" chip The "NeoViGen96" chip included genes coding for PR proteins $(n=28)$, enzymes involved in the synthesis of secondary metabolites (phenylpropanoids, terpenoids, $N=15$; and indole compounds $(N=5)$, in the oxido-reduction system $(N=5)$, in the ethylene or oxylipin/JA pathways $(N=4)$, cell wall reinforcement $(N=13)$ and other proteins involved in pathogen detection signaling and transcription signaling $(N=15)$

untreated blocks, respectively $(5.2 \% \pm 1.6$ and $12.4 \% \pm 2.5$ of downy mildew severity respectively compared to $39.3 \% \pm 2.8$ on untreated control). Area Under Disease Progress Curves (AUDPC) [48], which summarize repeated data such as the change in intensity of an epidemic as a unique value (AUDPC), were 55 and $45 \%$ lower than in untreated controls, respectively (Fig. 6).

As we observed in preliminary trials, significant effects with this treatment program were observed on the grapevine physiology (spilled flowering and ripening late, data not shown), analyses of yield and fruit quality were made at harvest carried out the 11th October 2011 (weight of harvested bunches, berry weight and $\mathrm{pH}$, acidity and sugar content of the must, Table 3). BTH and FOS had a significant protective effect on grapevine leaves $(5.2 \% \pm 1.6$ and $12.4 \% \pm 2.5$ of downy mildew severity respectively compared to $39.3 \% \pm 2.8$ on untreated control) and on grape berries $(2.82 \% \pm 0.83$ and $2.54 \% \pm 0.67$ of downy mildew severity respectively compared to $38.8 \% \pm 2.35$ on untreated control, data not shown) and the harvest was 3.3 times higher in the treated vines $(1637 \pm 280 \mathrm{~g}$ with $17.5 \pm 2.9$ clusters per stock) than in the untreated vines $(496 \pm 165 \mathrm{~g}$ with $8.5 \pm 2.3$ clusters by stock). The grapes harvested from plants treated with BTH were 2 times smaller than those harvested from plants treated with FOS but identical to grapes harvested in the untreated plants $(163.4 \pm 27.3 \mathrm{~g}$ and $336.5 \pm 33.4 \mathrm{~g}$ per cluster, respectively) with berries 1.5 times smaller than those of FOS-treated and untreated plants $(0.97 \pm 0.03 \mathrm{~g}$ $1.46 \pm 0.02 \mathrm{~g}$ by berry, respectively) (Table 3 ). No difference was observed in $\mathrm{pH}$, acidity and sugar in sugar content (Table 3).

We are quite aware that the field test presented in this study will never be used by the profession: it only served as a example to validate this tool for assessing grapevine defense status in the natural environment, and in no case to develop this alternative strategy (elicitor used).

The molecular tool used for several years in previous tests ("BioMolChem" chip or "qPFD" chip) was limited when we wanted to test the grapevine defense status in vineyard. We needed to increase the throughput of gene expression analyses.

We developed the Fluidgm tool, and in this paper, we underline its power, which has a throughput 60-70 times higher and uses amounts of cDNA 70-150 times smaller than with conventional qPCR assays. Only the second sample in this field trial was analyzed by the two technologies.

\section{Defense-related gene expressions in elicited grapevine leaves}

As the expected action of these potentially eliciting products is rather preventive than curative and because preliminary studies [26] showed that the pathogen diverts the plant metabolism in its favor and particular by blocking the deployment of its defenses, we chose a sampling protocol rather early in the season when the period of grapevine sensitivity against downy mildew is the strongest than later after the pathogen inoculation or once the epidemic is in place at a time when there was no real point in tracking the defense status of the vine. The grapevine defense reaction was analyzed $48 \mathrm{~h}$ after a second elicitor treatment applied in the vineyard. Twelve leaves at a similar stage were taken for each modality 2 days after the second treatment (see Methods, Fig. 5). Among the genes involved in pathogen detection- signaling- transcription, BTH induced (Relative Expression $(\mathrm{RE})>1.2$ ) the genes involved in the SA and ET pathways, with the SA-dependent (EDS1b) gene, SA-methyl transferase (SAMT1), the enzyme involved in ethylene biosynthesis $(A C O 1 a)$ and a transcription factor (WRKY2) (Table 3 and Fig. 7).

In the $\mathrm{PR}$ protein gene expressions, $\mathrm{BTH}$ treatment triggered the over-expression $(R E>1.2)$ of $P R 1$ transcripts (PR1 and 1bis), glucanases (PR2 and GLU), chitinases (PR3, CHIT3, CHIT4 and PR4), serine protease (PR6 and 6bis) and the repression $(R E<0.8)$ of the other serine protease $(P I N)$. BTH treatment also led to the repression of subtilisin-like endoproteases (PR7-7bis), ribonuclease-like $(P R 10)$, defensin-like $(P R 12)$ and the germin-like protein- oxalate oxidase genes (PR15-15bis) (Table 4 and Fig. 7). Among the genes involved in cell wall reinforcement, $\mathrm{BTH}$ led to the up-regulation $(R E>1.2)$ of coniferyl alcohol glucosyl transferase (CAGT) and lignin forming peroxidase $(P E R)$ and to the repression $(R E<0.8)$ of the other CAGT2. BTH also led to the up-regulation $(R E>1.2)$ of allinase (Alli2) which is involved in the production of volatile compounds. 


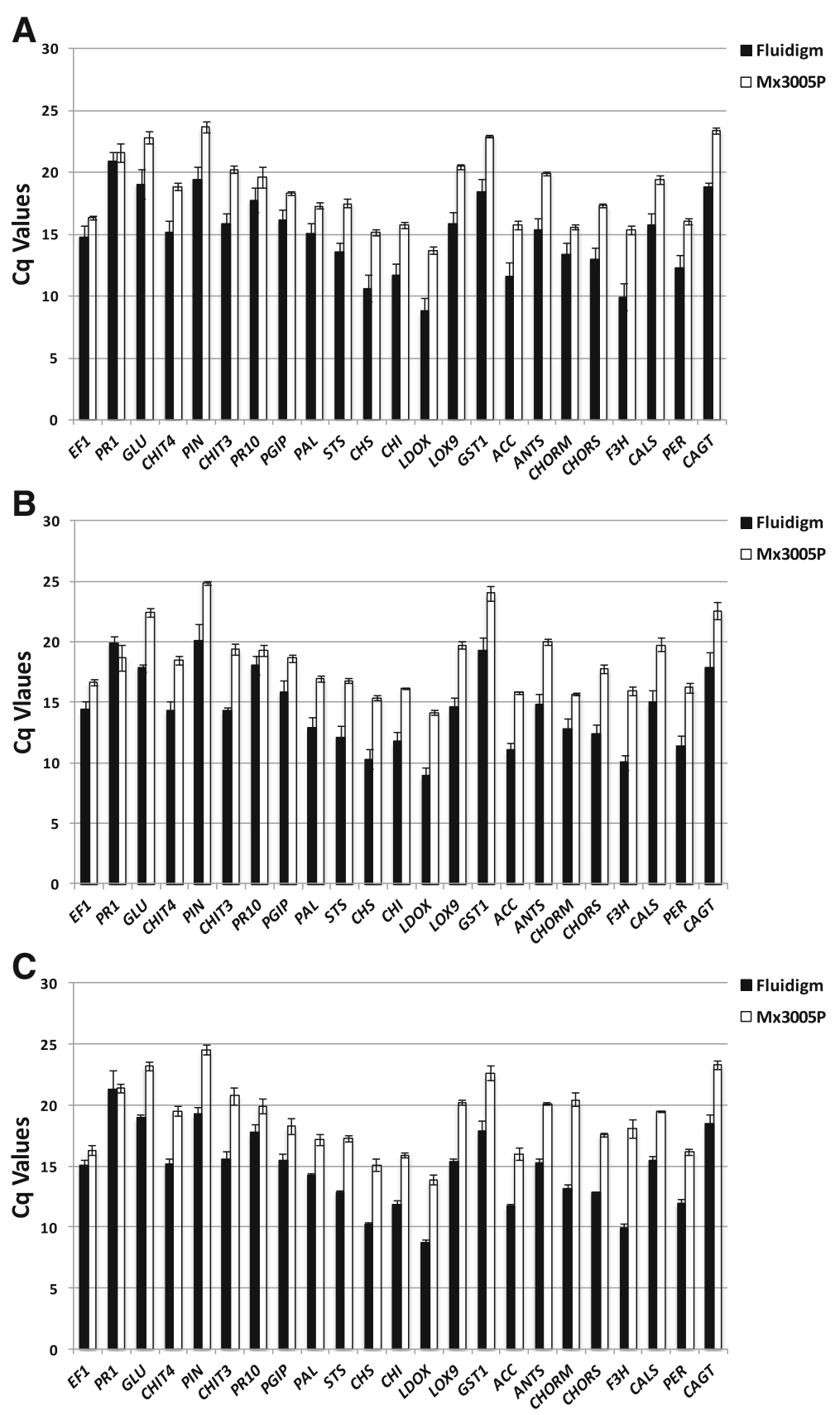

Fig. 2 Cq value comparisons using 96.96 dynamic array and Stratagene Mx3005P. cDNAs were synthesized using polydT ${ }_{(15)}$ primers and $10 \mu g$ of total RNA from leaves untreated (a) or treated with BTH (b), Fosetyl-Al (c). Bars represent the means of Ct values from three biological replicates. Open bars: Stratagene MX3005P system and closed bars: 96.96 Fluidigm dynamic array

Results also showed the differential expression of genes involved in the pathways of secondary metabolites, indoles and ET/JA (Table 4 and Fig. 7), with the over-expression of genes involved in stilbene biosynthesis (PAL, STS, $R O M T$ ), in isoprenoid biosynthesis (FAR) and in oxylipin/ JA biosynthesis (LOX9 and LOX3) and the repression of genes involved in flavonoid biosynthesis $(\mathrm{CHI}$ and $\mathrm{CHI} 2$,
$L D O X$ and $F 3 H$ ), in the indole pathway (CHORS2) and in redox status (GST1 and GST4).

BTH treatment induced the modulation of $14.1 \%$ of the studied genes, $58.3 \%$ of them being up-regulated with significant over-expression of genes coding for PR1-1bis, PR2, PAL and STS and significant repression of gene coding for PR7bis and LDOX and F3H (Table 5). 


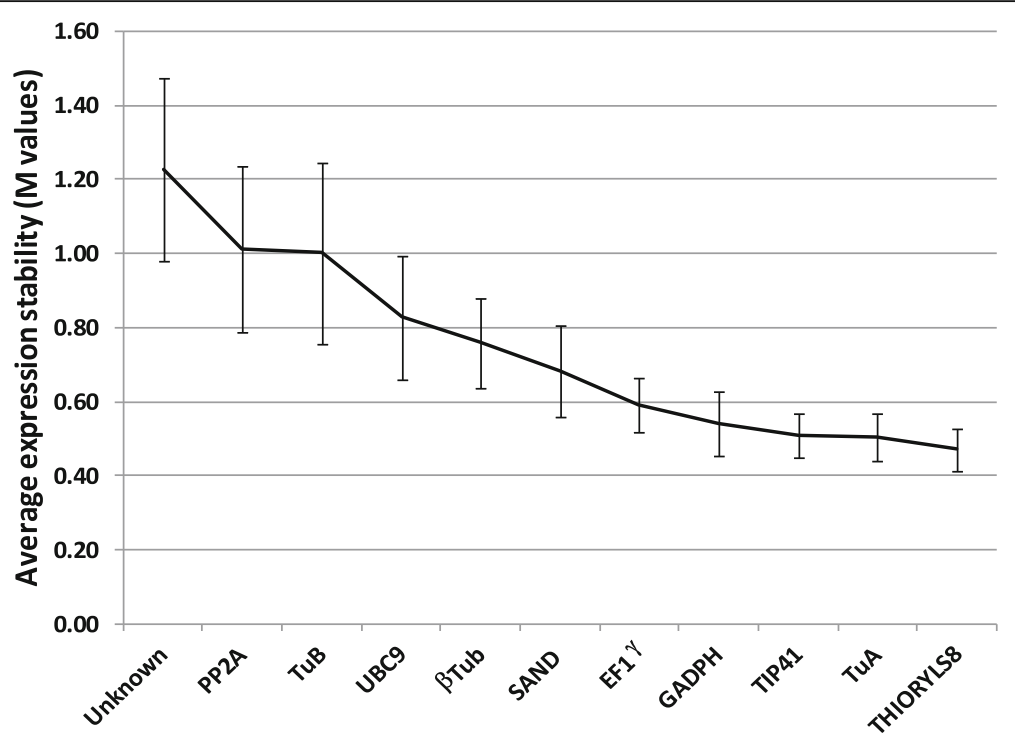

Fig. 3 Expression stability mean values (M-values). $M$ values of 11 endogenous control genes in leaf samples using the principles and formulas described by Vandesompele. [47] Values are means \pm SD of 15 independent microfluidic dynamic arrays

All of these results corroborated our previous study showing that BTH enhances resistance against Plasmopara viticola by up-regulating the PR proteins (PR1, PR2 and $P R 3$ ). The most induced gene was $P R 1$ which is usually reported to be a typical marker of SAR [49]. A rapid over-expression of three genes coding for key enzymes was observed in the phenylpropanoid pathway ( $P A L$ and $S T S)$ and in the SA biosynthesis pathway $(P A L)$. One GST gene coding for an enzyme involved in the redox status of the plant and an $A C C$ gene involved in the ethylene pathway were also strongly up-regulated. [26]
The same defense response pathway may therefore be observed in grapevine leaves in the vineyard to that observed in laboratory conditions.

Upon FOS treatment, only the EDS1a, ACO1a genes were significantly up-regulated and a significant repression of an EIN3-dependent regulation of plant ethylene hormone signaling (EIN3bis) and genes coding for important components of the resistance gene JA-dependent (JAR2) was observed.

The expression level of defense-related genes in FOS-treated leaves was less intense with only $8.2 \%$ of

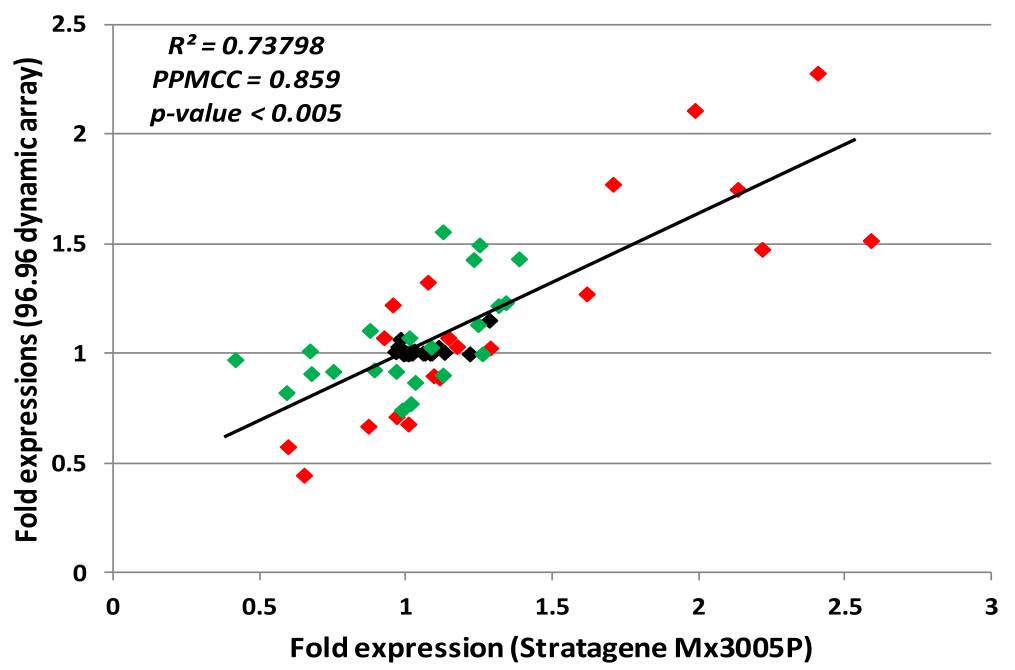

Fig. 4 Correlation scatter plots of fold expression of "BioMolChem" chip genes $(n=24)$ using Stratagene or Biomark HD systems obtained with three replicates of leaves treated with BTH (red), with FOS (green) or untreated (black). Correlation of fold expression obtained by Stratagene MX3005P system (x axis) and microfluidic dynamic array (y axis). $R^{2}=$ coefficient of correlation of the simple linear regression, PPMCC $=$ Pearson product-moment correlation coefficient (Pearson's correlation). Significant correlation was determined at a level of $p$-value $<0.05$ 


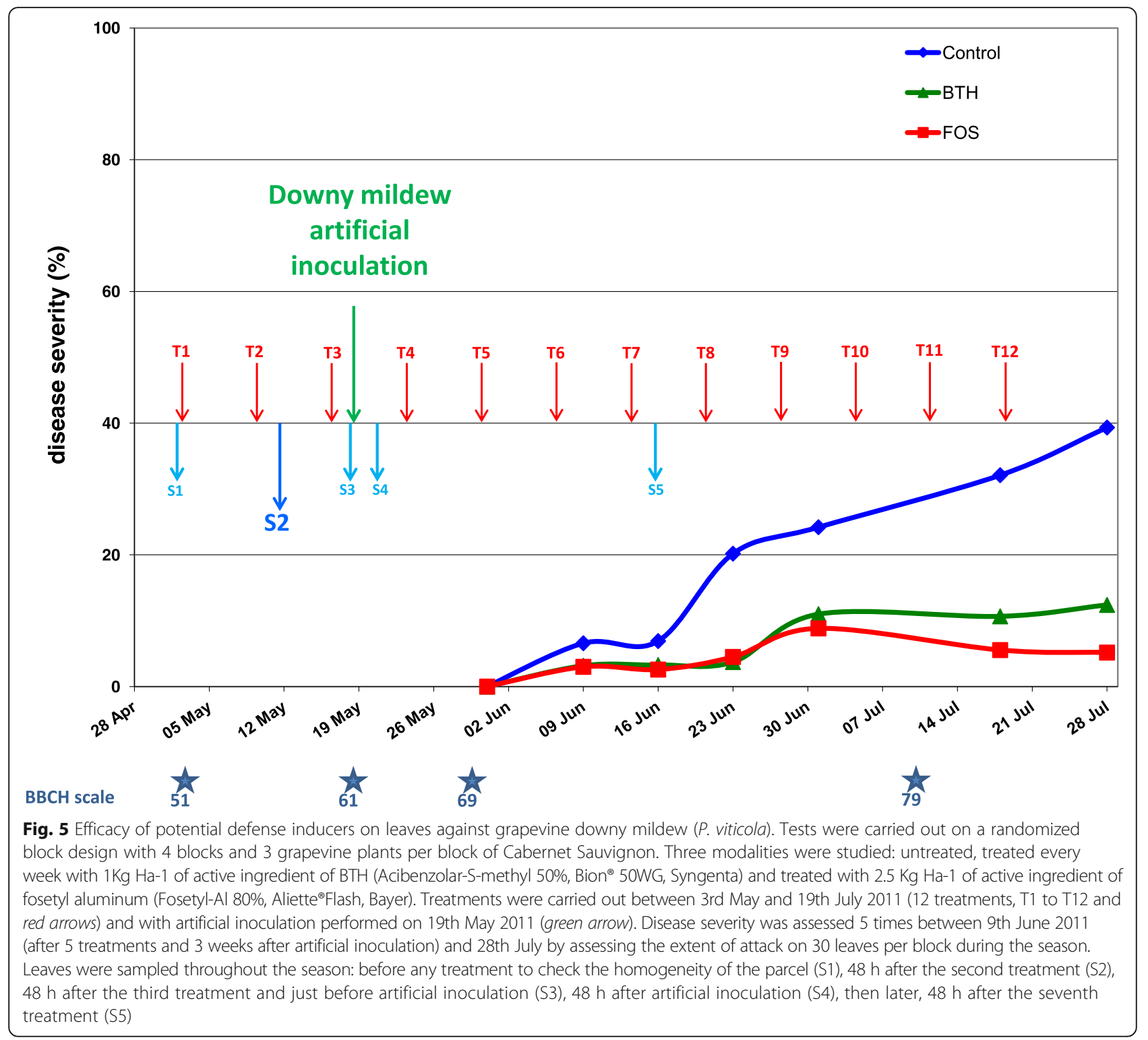

differentiated genes, $25 \%$ of them being up-regulated. FOS treatment induced a less strong over-expression of PR1-PR2 (significant in BTH-treated but not in FOS-treated) and the repression of $P R 3$ while it was over-expressed with BTH, and a less strong repression of PR7bis. Genes encoding PR7- PR12 and PR15 in BTH-treated leaves were repressed while they were over-expressed with FOS treatment. Two major genes in the biosynthetic pathway of phenylpropanoids ( $P A L$ and $S T S$ ) were significantly over-expressed in leaves treated with BTH while only $P A L$, which is also involved in the SA pathway, was differentially over-expressed in FOS-treated leaves, with expression levels two-fold and five-fold higher in BTH-treated leaves than in FOS-treated ones and untreated controls, respectively. Similarly, two major genes of the biosynthetic pathway of stilbene ( $P A L$ and STS) were strongly linked to resistance induced by BTH.

These results are in agreement with data obtained in previous experiments conducted in controlled laboratory conditions $[16,17]$ and also in another where $P A L$ and STS were reported to be major genes in the resistance of Vitis vinifera [50].

Principal Component Analysis (PCA) was used to summarize the ways in which gene defense responses vary after elicitation. Most of the variance in the defense expression dataset was contained in the first two principal components which captured $\sim 60 \%$ of the total variability (Additional file 3). Results of PCA based on the subset of the 24 Vitis vinifera defense-related genes common to the two technologies (Tables 1 and 2) summarized the 18 samples projected on the two principal 


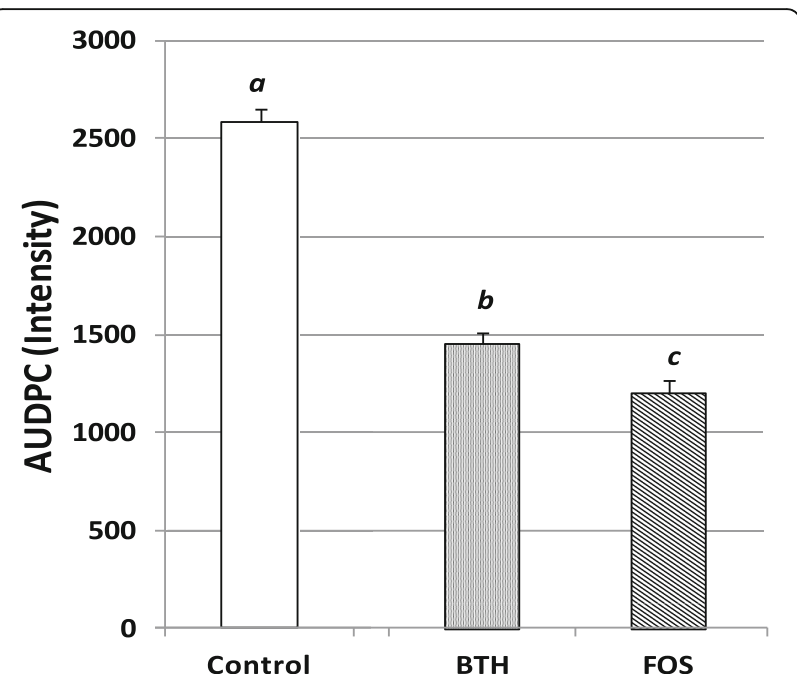

Fig. 6 Area under the disease progress curve (AUDPC). Data from disease progression curves from 9th June to 28th July 2011 were transformed in a single value by a formula developed by Simko and Piepho [48], the area under the disease progress curve (AUDPC). Values are means \pm SD of AUDPC obtained

components (Fig. 8). Statistical similarities analysis (ANOSIM) showed no significant difference between gene-expression analyses performed with Fluidigm microfluidics dynamic arrays (squared samples) and the Stratagene Mx3005P qPCR system (triangular samples) $(p=0.95)$. The axis 1 discriminates BTH- treated modalities treated of all other modalities (control and FOS-treated), marked by a significant over expression of STS-PAL-LOX-GLU-CHIT3-PER and CHIT4 genes and significant repression CHI-PGIP-LDOX-F3H-GST and $P I N$ genes in these samples. By cons, although variables Pr10-ANTS-CHI-ACC-CHIT4-LDOX-PR1-CHIT3$G L U$ and $C A L S$ genes contribute significantly to the axis 2 , no particular modality was significantly correlated with this axe 2 (Fig. 8). Confidence ellipses around the categories of treatments revealed two significant clusters: Cluster A with control and FOS-treated samples and Cluster B only with BTH-treated samples.

Gene expression analyses made on leaves sampled $48 \mathrm{~h}$ after downy mildew inoculation (S4, Fig. 5) showed that the BTH treatment continued to modulate $33.3 \%$ of the studied genes ( $N=24$ in Stratagene system), $87 \%$ of them being up-regulated (data not shown). The significant efficacy of the BTH treatment seems to be due to the stimulation of grapevine defenses, although the level of protection it provides is lower than with FOS.

On the other hand, the grapevine defense responses to the downy mildew attack in FOS-treated plants resulted in a modulation of $71 \%$ genes studied and $83 \%$ were significantly repressed (data not shown). These results are consistent with previous studies [26], where the pathogen modulated the plant defenses in its favor, including suppressing the defense genes. At the concentration used (2.5 kG Ha-1), the FOS efficiency observed in this trial is probably mostly due to a fungicide effect in view of the low level of defense-related gene expression compared to the untreated control.

\section{Conclusions}

In this paper we report the development of a new highthroughput Q-PCR methodology adapted to monitor grape defense responses. With the Stratagene system and the "BioMolChem" chip, 2 samples were analyzed with 24 primer sets (48 data) by real-time RT-qPCR. The time to run one plate in this system is $1: 30 \mathrm{~h}$. With the Biomark HD system, it is possible to obtain 9216 data (96 samples matched with 96 primer sets) in $4 \mathrm{~h}$. This new flexible method has a throughput 60-70 times higher and uses amounts of cDNA 70-150 times smaller. Furthermore, the samples and reagents used are approximately 6 times cheaper than with conventional assays.

The "NeoViGen96" chip allowed us to demonstrate the defense-stimulating effect of BTH in the vineyard, leading to a partial but significant protection against downy mildew. With FOS, the grapevine protection obtained against downy mildew in the vineyard could not be explained by weak elicitor activity so this suggests that it has a strong fungicide action in our hands.

It is now possible to obtain better and easier understanding of grapevine responses to elicitation in the field. The potential of elicitors can be exploited by combining them in innovative pest management programs in association or in alternation with conventional fungicides in order to reduce the use of fungicides.

\section{Methods \\ Plant materials and treatments}

Experiments were carried out in the experimental vineyard of Couhins which covers 45 ha and is located near Bordeaux (Pessac-Léognan appellation). The soil

Table 3 Assessment of the yield and the fruit quality at the harvest carried out on 11th October 2011

\begin{tabular}{|c|c|c|c|c|c|c|}
\hline & $\begin{array}{l}\text { mean weight harvested } \\
\text { by stock (g) }\end{array}$ & cluster mean weight (g) & berry mean weight (g) & sugar content (g/L) & Acidity & $\mathrm{pH}$ \\
\hline Control untreated & $496,7 \pm 164,6 \boldsymbol{a}$ & $133,3 \pm 38,0 \boldsymbol{a}$ & $1,46 \pm 0,03 \boldsymbol{b}$ & $175,8 \pm 0,7 \boldsymbol{a}$ & $4,2 \pm 0,04 \boldsymbol{a}$ & $3,3 \pm 0,04 a$ \\
\hline BTH treated & $1480,0 \pm 296,1 \boldsymbol{b}$ & $193,6 \pm 21,4 \boldsymbol{a}$ & $0,97 \pm 0,03 \boldsymbol{a}$ & $180,9 \pm 2,2 \boldsymbol{a}$ & $4,0 \pm 0,13 \boldsymbol{a}$ & $3,4 \pm 0,13 \boldsymbol{a}$ \\
\hline FOS treated & $1794,2 \pm 262,9 \boldsymbol{b}$ & $336,5 \pm 33,1 \boldsymbol{b}$ & $1,47 \pm 0,01 \boldsymbol{b}$ & $174,9 \pm 0,2 \boldsymbol{a}$ & $4,2 \pm 0,02 \boldsymbol{a}$ & $3,2 \pm 0,02 \boldsymbol{a}$ \\
\hline
\end{tabular}

Values with the same letter are not statistically different at a threshold of $0.05 \%$ 


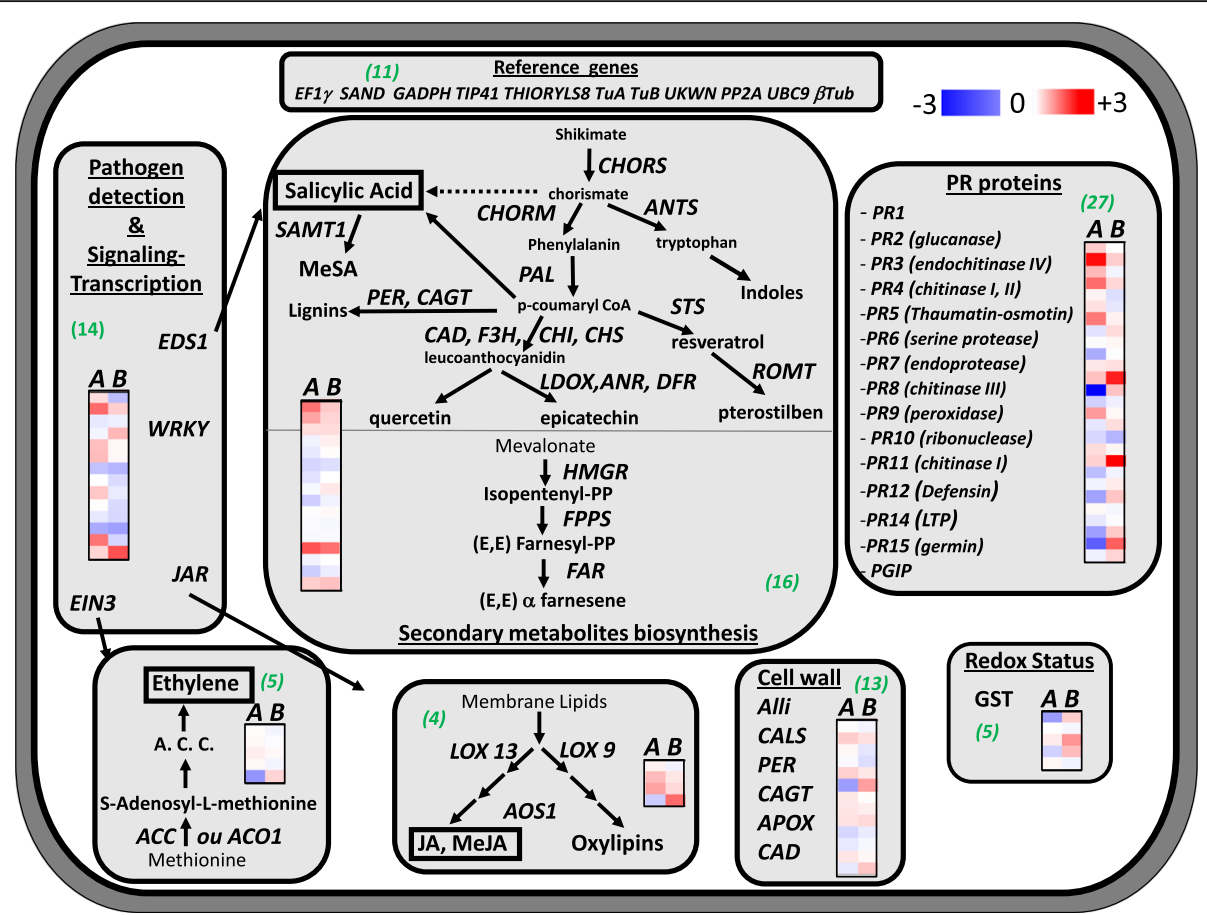

Fig. 7 "Heatmap" representing relative expression of genes in $\log _{2}$ transformations. Expression levels of 85 defense-related genes involved in pathogen detection-signaling-transcription $(n=10)$, in secondary metabolite biosynthesis $(n=26)$, coding for PR-proteins $(n=29)$, involved in cell wall reinforcement $(n=13)$, in oxylipins/JA and ET biosynthesis $(n=3)$ and redox status $(n=5)$ were assessed using a relative method with multiple-gene normalization (11 genes) in grapevine leaves treated with BTH (a) or FOS (b) compared to untreated leaves. Values are means \pm SD of three independent biological replicates. The color gradient leading to blue for genes repressed $\left(\log _{2}(R E)<0\right)$, to red for genes over-expressed $\left(\log _{2}(R E)>0\right)$ and white for genes exhibiting no modification in their expression ( $\left.\log _{2}(R E)=0\right)$. Numbers in brackets: number of genes involved in the function

is composed of a layer of clay on limestone that is very well suited to Cabernet Sauvignon grafted onto the Fercal rootstock. Double Guyot management provides good leaf distribution and spread.

Tests were carried out on a randomized block design with 4 blocks and 3 grapevine plants per block of Cabernet Sauvignon. Three conditions were studied: untreated, treated every week with $1 \mathrm{Kg} \mathrm{Ha}^{-1}$ of active ingredient of BTH (Acibenzolar-S-methyl 50\%, Bion 50WG, Syngenta) and treated with $2.5 \mathrm{Kg} \mathrm{Ha}^{-1}$ of active ingredient of fosetyl aluminum (Fosetyl-Al 80\%, Aliette ${ }^{\circ}$ Flash, Bayer).

The treatments began on 3rd May 2011 at the phenological stage $13-14$ on the $\mathrm{BBCH}$ scale (3-4 leaves unfolded) and were stopped on 19th July 2011at stage 79 (fruits and berries have reached final size) after 12 treatments. Plasmopara viticola was artificially inoculated on 19th May 2011 at stage 55 (inflorescence swelling, flowers closely pressed together), $24 \mathrm{~h}$ after the fourth treatment, by spraying 6 leaves with a solution of sporangia (25 000-45 000 sporangia $\mathrm{mL}^{-1}$ ). Twelve leaves at a similar stage were taken for each assay on 12th May 2011 ( 2 days after the second treatment on 10th May), divided into three biological repetitions of four leaves and were frozen at $-80{ }^{\circ} \mathrm{C}$ until use for molecular analysis.
Five leaf samplings were performed throughout the season: before treatment to check the homogeneity of the parcel (S1), $48 \mathrm{~h}$ after the second treatment (S2), $48 \mathrm{~h}$ after the third treatment and just before artificial inoculation (S3), $48 \mathrm{~h}$ after artificial inoculation (S4), then later, $48 \mathrm{~h}$ after the seventh treatment (S5). In this article we report only the results obtained with the second sampling, prior to $\mathrm{P}$. viticola inoculation, which was the only one to be analyzed with both technologies (Stratagene and BiomarkHD).

Field study of fosetyl aluminum and BTH effects on downy mildew disease

The progress of the disease was observed several times throughout the epidemic. The downy mildew disease severity (average percentage of attack) was assessed 6 times, beginning on 9th June after 6 treatments, 4 weeks after artificial inoculation, and around 18th July (Fig. 5) by assessing the level of attack of 30 leaves per block according to the CEB method No. 007: Method of practical effectiveness for fungicide tests designed to fight against downy mildew (Plasmopara viticola (B. C) Berl and Tomi). 
Table 4 Relative expression of defense-related genes in "NeoViGen96" chip

\begin{tabular}{|c|c|c|c|c|c|c|c|}
\hline & \\
\hline Genes & Control & BTH-treated & FOS-treated & $\overline{C H O R M}$ & $1.00 \pm 0.10$ & $1.07 \pm 0.24$ & $0.98 \pm 0.11$ \\
\hline$\overline{P R 1}$ & $1.15 \pm 0.69$ & $1.52 \pm 0.34$ & $1.00 \pm 1.05$ & CHORM2 & $1.00 \pm 0.07$ & $1.16 \pm 0.30$ & $1.06 \pm 0.11$ \\
\hline PR1 bis & $1.00 \pm 0.09$ & $7.37 \pm 2.81$ & $1.51 \pm 0.69$ & CHORS & $1.00 \pm 0.04$ & $1.07 \pm 0.10$ & $0.92 \pm 0.06$ \\
\hline GLU & $1.01 \pm 0.21$ & $1.77 \pm 0.66$ & $0.92 \pm 0.09$ & CHORS2 & $1.10 \pm 0.51$ & $0.42 \pm 0.03$ & $1.43 \pm 1.81$ \\
\hline$P R 2$ & $1.01 \pm 0.12$ & $3.31 \pm 1.32$ & $1.39 \pm 0.64$ & GST1 & $1.00 \pm 0.05$ & $0.45 \pm 0.26$ & $1.50 \pm 0.92$ \\
\hline$P R 3$ & $1.01 \pm 0.18$ & $1.12 \pm 0.23$ & $0.77 \pm 0.12$ & GST2 & $1.00 \pm 0.09$ & $0.54 \pm 0.11$ & $0.93 \pm 0.22$ \\
\hline CHIT4a & $1.01 \pm 0.14$ & $1.28 \pm 0.13$ & $0.82 \pm 0.17$ & GST3 & $1.08 \pm 0.55$ & $1.18 \pm 0.20$ & $2.40 \pm 2.89$ \\
\hline$P R 4$ & $1.01 \pm 0.20$ & $2.99 \pm 0.98$ & $1.13 \pm 0.36$ & GST4 & $1.02 \pm 0.23$ & $0.69 \pm 0.22$ & $1.74 \pm 0.07$ \\
\hline PR4bis & $1.01 \pm 0.20$ & $0.80 \pm 0.29$ & $1.34 \pm 0.99$ & GST5 & $1.01 \pm 0.17$ & $1.08 \pm 0.37$ & $0.91 \pm 0.23$ \\
\hline PR5bis & $1.00 \pm 0.11$ & $0.98 \pm 0.18$ & $1.08 \pm 0.21$ & LOX2 & $1.03 \pm 0.29$ & $1.13 \pm 0.56$ & $0.90 \pm 0.08$ \\
\hline PIN & $1.00 \pm 0.07$ & $0.51 \pm 0.21$ & $1.01 \pm 0.42$ & LOXO & $1.00 \pm 0.11$ & $1.75 \pm 0.17$ & $1.23 \pm 0.21$ \\
\hline PR6 & $1.04 \pm 0.32$ & $1.23 \pm 0.44$ & $1.30 \pm 0.18$ & LOX3 & $1.01 \pm 0.20$ & $2.15 \pm 0.26$ & $1.38 \pm 0.34$ \\
\hline PR6bis & $2.74 \pm 3.94$ & $1.67 \pm 1.07$ & $6.31 \pm 10.45$ & LOX4 & $1.05 \pm 0.37$ & $0.66 \pm 0.27$ & $3.35 \pm 4.80$ \\
\hline$P R 7$ & $1.24 \pm 0.94$ & $0.01 \pm 0.00$ & $1.64 \pm 2.43$ & Alli & $1.00 \pm 0.02$ & $1.04 \pm 0.10$ & $0.92 \pm 0.13$ \\
\hline PR7 bis & $1.01 \pm 0.20$ & $0.69 \pm 0.05$ & $0.88 \pm 0.08$ & Alli2 & $1.02 \pm 0.28$ & $1.52 \pm 0.12$ & $1.29 \pm 0.18$ \\
\hline CHIT3 & $1.04 \pm 0.34$ & $2.28 \pm 0.93$ & $1.07 \pm 0.42$ & APOX & $1.00 \pm 0.07$ & $1.08 \pm 0.27$ & $0.82 \pm 0.11$ \\
\hline PR8 & $1.04 \pm 0.39$ & $0.82 \pm 0.09$ & $1.32 \pm 0.97$ & $A P O X 2$ & $1.01 \pm 0.21$ & $0.96 \pm 0.18$ & $0.76 \pm 0.14$ \\
\hline POX & $1.06 \pm 0.45$ & $0.73 \pm 0.27$ & $0.55 \pm 0.25$ & CAGT & $1.07 \pm 0.42$ & $1.47 \pm 0.45$ & $1.22 \pm 0.66$ \\
\hline PR9-b & $1.25 \pm 1.04$ & $1.45 \pm 1.38$ & $17.97 \pm 27.30$ & CAGT2 & $1.12 \pm 0.68$ & $0.45 \pm 0.08$ & $2.20 \pm 2.92$ \\
\hline PR10 & $1.00 \pm 0.05$ & $0.59 \pm 0.03$ & $0.91 \pm 0.35$ & CALS & $1.01 \pm 0.16$ & $1.22 \pm 0.12$ & $1.03 \pm 0.27$ \\
\hline PR11 & $1.00 \pm 0.12$ & $0.91 \pm 0.28$ & $1.18 \pm 0.63$ & CALS2 & $1.04 \pm 0.33$ & $1.23 \pm 0.20$ & $1.15 \pm 0.11$ \\
\hline PR12 & $1.01 \pm 0.21$ & $0.47 \pm 0.11$ & $1.61 \pm 1.17$ & CALS3 & $1.06 \pm 0.46$ & $1.27 \pm 0.65$ & $1.38 \pm 0.28$ \\
\hline PR14 & $1.02 \pm 0.25$ & $1.07 \pm 0.17$ & $0.93 \pm 0.09$ & $P E R$ & $1.01 \pm 0.13$ & $1.33 \pm 0.06$ & $1.10 \pm 0.21$ \\
\hline PR 14bis & $1.02 \pm 0.23$ & $0.83 \pm 0.06$ & $0.98 \pm 0.18$ & PECT1 & $1.17 \pm 0.83$ & $0.72 \pm 0.44$ & $0.85 \pm 0.32$ \\
\hline PR15 & $1.19 \pm 0.69$ & $0.46 \pm 0.15$ & $1.55 \pm 1.45$ & PECT2 & $1.00 \pm 0.09$ & $0.84 \pm 0.08$ & $0.94 \pm 0.09$ \\
\hline PR15bis & $1.39 \pm 1.11$ & $0.27 \pm 0.23$ & $3.72 \pm 6.41$ & $C A D$ & $1.01 \pm 0.16$ & $1.24 \pm 0.03$ & $1.08 \pm 0.18$ \\
\hline PGIP & $1.03 \pm 0.30$ & $0.89 \pm 0.21$ & $1.43 \pm 0.56$ & $C A D 2$ & $1.08 \pm 0.53$ & $0.83 \pm 0.15$ & $1.60 \pm 1.51$ \\
\hline PAL & $1.00 \pm 0.06$ & $3.17 \pm 0.24$ & $1.56 \pm 0.35$ & EDS1a & $1.00 \pm 0.06$ & $1.33 \pm 0.32$ & $0.59 \pm 0.12$ \\
\hline STS & $1.01 \pm 0.17$ & $2.11 \pm 0.43$ & $1.43 \pm 0.18$ & $E D S 16$ & $1.00 \pm 0.04$ & $3.36 \pm 0.44$ & $1.50 \pm 0.60$ \\
\hline$R O M T$ & $1.00 \pm 0.10$ & $1.32 \pm 0.65$ & $1.34 \pm 0.65$ & EDS1C & $1.01 \pm 0.14$ & $0.83 \pm 0.08$ & $0.88 \pm 0.19$ \\
\hline $\mathrm{CHS}$ & $1.00 \pm 0.11$ & $0.90 \pm 0.21$ & $1.14 \pm 0.11$ & WRKY1 & $1.01 \pm 0.19$ & $0.92 \pm 0.20$ & $1.80 \pm 2.12$ \\
\hline CHS2 & $1.00 \pm 0.09$ & $0.83 \pm 0.14$ & $1.03 \pm 0.15$ & WRKY2 & $1.00 \pm 0.08$ & $1.69 \pm 0.09$ & $1.08 \pm 0.32$ \\
\hline $\mathrm{CHI}$ & $1.01 \pm 0.13$ & $0.71 \pm 0.17$ & $0.77 \pm 0.15$ & $J A R$ & $1.04 \pm 0.32$ & $1.73 \pm 0.84$ & $1.07 \pm 0.18$ \\
\hline $\mathrm{CHI} 2$ & $1.01 \pm 0.14$ & $0.80 \pm 0.13$ & $1.00 \pm 0.08$ & JAR2 & $1.01 \pm 0.20$ & $0.61 \pm 0.06$ & $0.55 \pm 0.19$ \\
\hline$D F R$ & $1.02 \pm 0.24$ & $0.95 \pm 0.17$ & $1.21 \pm 0.32$ & ACO1 & $1.01 \pm 0.13$ & $1.00 \pm 0.16$ & $0.75 \pm 0.05$ \\
\hline LDOX & $1.01 \pm 0.14$ & $0.68 \pm 0.09$ & $0.90 \pm 0.17$ & ACO1b & $1.02 \pm 0.24$ & $1.58 \pm 0.10$ & $0.85 \pm 0.25$ \\
\hline$P P O$ & $1.08 \pm 0.46$ & $0.99 \pm 0.19$ & $1.05 \pm 0.37$ & $A C C$ & $1.01 \pm 0.15$ & $1.03 \pm 0.23$ & $0.74 \pm 0.03$ \\
\hline$H M G R$ & $1.01 \pm 0.16$ & $0.97 \pm 0.09$ & $0.94 \pm 0.10$ & EIN3 & $1.01 \pm 0.16$ & $0.83 \pm 0.11$ & $0.73 \pm 0.06$ \\
\hline FPPS & $1.01 \pm 0.17$ & $0.95 \pm 0.17$ & $0.96 \pm 0.16$ & EIN3bis & $1.01 \pm 0.15$ & $0.50 \pm 0.11$ & $0.46 \pm 0.12$ \\
\hline$F A R$ & $1.02 \pm 0.22$ & $4.08 \pm 2.97$ & $3.20 \pm 3.84$ & SAMT1 & $1.01 \pm 0.20$ & $3.10 \pm 1.60$ & $0.71 \pm 0.10$ \\
\hline FAR2 & $1.03 \pm 0.29$ & $0.91 \pm 0.20$ & $1.00 \pm 0.28$ & AOS1 & $1.52 \pm 1.14$ & $1.41 \pm 0.63$ & $4.16 \pm 5.17$ \\
\hline
\end{tabular}

Table 4 Relative expression of defense-related genes in "NeoViGen96" chip (Continued)

$\begin{array}{llll}\text { HSR203J } & 1.06 \pm 0.40 & 1.50 \pm 0.34 & 1.66 \pm 0.75\end{array}$

ANTS

$1.01 \pm 0.13 \quad 1.03 \pm 0.10$

$0.92 \pm 0.17$ 
Table 5 Relative expression of defense-related genes that were significantly induced (bold and italic) or repressed (italic and underlined) in leaves treated with BTH and FOS in comparison with untreated controls sampled $48 \mathrm{~h}$ after the second treatement (S2) at the threshold of $0.05 \%$

\begin{tabular}{lll}
\hline & BTH & FOS \\
\hline PR1 bis & $\mathbf{7 . 3 7}$ & - \\
PR2 & 3.31 & - \\
PR7 bis & $\underline{0.69}$ & $\underline{0.88}$ \\
PAL & $\mathbf{3 . 1 7}$ & $\mathbf{1 . 5 6}$ \\
STS & $\mathbf{2 . 1 1}$ & - \\
LDOX & $\underline{0.68}$ & - \\
F3H & $\underline{0.67}$ & - \\
GST2 & - & $\underline{0.93}$ \\
GST4 & - & 1.74 \\
LOX9 & $\mathbf{1 . 7 5}$ & - \\
EDS1b & $\mathbf{3 . 3 6}$ & - \\
JAR2 & $\underline{0.61}$ & $\underline{0.55}$ \\
ACO1b & $\mathbf{1 . 5 8}$ & - \\
EIN3 & - & $\underline{0.73}$ \\
EIN3bis & $\underline{0.50}$ & $\underline{0.46}$ \\
\% of differentiated genes & $\mathbf{1 4 . 1}$ & $\mathbf{8 . 2}$ \\
Relative \% of up-regulated genes & $\mathbf{5 8 . 3}$ & $\mathbf{2 5}$ \\
\hline
\end{tabular}

Data from a disease progress curve were transformed into a single value by a formula developed by Simko and Piepho [48] which calculates the area under the disease progress curve (AUDPC):

$$
A U D P C=\sum_{(i=1)}^{(n-1)} \frac{\mathrm{y}_{\mathrm{i}}+\mathrm{y}_{\mathrm{i}+1}}{2} \times\left(\mathrm{t}_{\mathrm{i}+1}-\mathrm{t}_{\mathrm{i}}\right)
$$

All clusters of each experimental block were collected on 11th October 2011, counted and weighed to assess the yield. This allowed the evaluation of the average number of bunches produced per vine stock as well as the average weight of bunches. In addition, berries randomly picked by modality were weighed to assess the average weight of a berry.

To assess the harvest quality, 3 batches of 3 clusters per modality were crushed and the sugar content, $\mathrm{pH}$ and acidity of must obtained were measured. The $\mathrm{pH}$ was measured with a pHmeter, the acidity was determined by the volume of $\mathrm{NaOH}(0.1 \mathrm{~N})$ required to adjust the $\mathrm{pH}$ of the must to 7 and the sugar content was measured with a Brix refractometer (a Brix degree correspond to $1 \%$ of sucrose in the solution).

\section{PCR primer pairs}

The most recent molecular information available for designing a Biomark assay can provide valuable results in terms of pathways involved in the response of the plant to the pathogen.

The mRNA sequences of the genes studied were taken from the National Center for Biotechnology Information (NCBI) Gene Database or from the Kyoto Encyclopedia of Genes and Genomes (KEGG) pathway Database with Vitis vinifera (Wine grape) as reference genome. For primer design, the Primer3 free software (http://bioinfo.ut.ee/ primer3-0.4.0/) was used.

The specificity of the primer pairs was checked by melting curve analysis and gel electrophoresis of the amplified product (data not shown). PCR efficiencies of the assays were determined with a 5-point dilution series of a pool of samples from the experiment in qPCR triplicates, in agreement with Bustin et al.[51]. The gene names and symbols, their corresponding accession numbers and the primer sequences that were used are listed in (Tables 1 and 2).

\section{RNA extraction and reverse transcription}

RNA extraction was performed according to the protocol described by Reid et al. [52] from frozen leaves of three biological replicates per treatment (untreated, BTH and FOS) stored at $80{ }^{\circ} \mathrm{C}$. A total of 9 samples formed by 4 leaves were extracted. After grinding in liquid nitrogen, leaf powder was added to an extraction buffer (20 g.mL -1) preheated to $56{ }^{\circ} \mathrm{C}$ (300 mM Tris $\mathrm{HCl}$, pH 8.0, 25 mM EDTA, 2 mM NaCl 2\% CTAB, 2\% poly -vinyl poly-pyrrolidone (PVPP), $0.05 \%$ spermidine trihydrochloride and $2 \% \beta$-mercaptoethanol added extemporaneously). The mixture was stirred vigorously and incubated in a water bath at $56{ }^{\circ} \mathrm{C}$ for $10 \mathrm{~min}$ under regular stirring. An equal volume of chloroform: isoamyl alcohol $(24: 2, \mathrm{v} / \mathrm{v})$ was added and then centrifuged at $3500 \mathrm{~g}$ for $15 \mathrm{~min}$ at $4{ }^{\circ} \mathrm{C}$.

The following RNA extraction steps were conducted using the Spectrum ${ }^{\mathrm{TM}}$ Plant Total RNA Kit protocol: RNA was captured onto a binding column using a unique binding solution, which effectively prevents polysaccharides as well as genomic DNA from clogging the column. Residual impurities and the most residual genomic DNA were removed by DNase treatment according to the manufacturer's procedure and with wash solutions. Purified RNAs were eluted in RNase-free water. The amounts of RNA obtained were measured at $260 \mathrm{~nm}$ and $280 \mathrm{~nm}$ by spectrometry (NanoDrop 1000 Spectrophotometer, France). RNA integrity was assessed either by electrophoresis on an agarose gel or by passage over a Bioanalyzer (Agilent technology, France). RT-qPCR was conducted according to the MIQE (minimum information for publication of quantitative real-time PCR experiments) guidelines [51].

Ten micrograms were reverse-transcribed using $2 \mu \mathrm{M}$ oligo-d $(\mathrm{T})_{15}$, ribonuclease inhibitor and M-MLV reverse transcriptase (Promega, France) according to the 


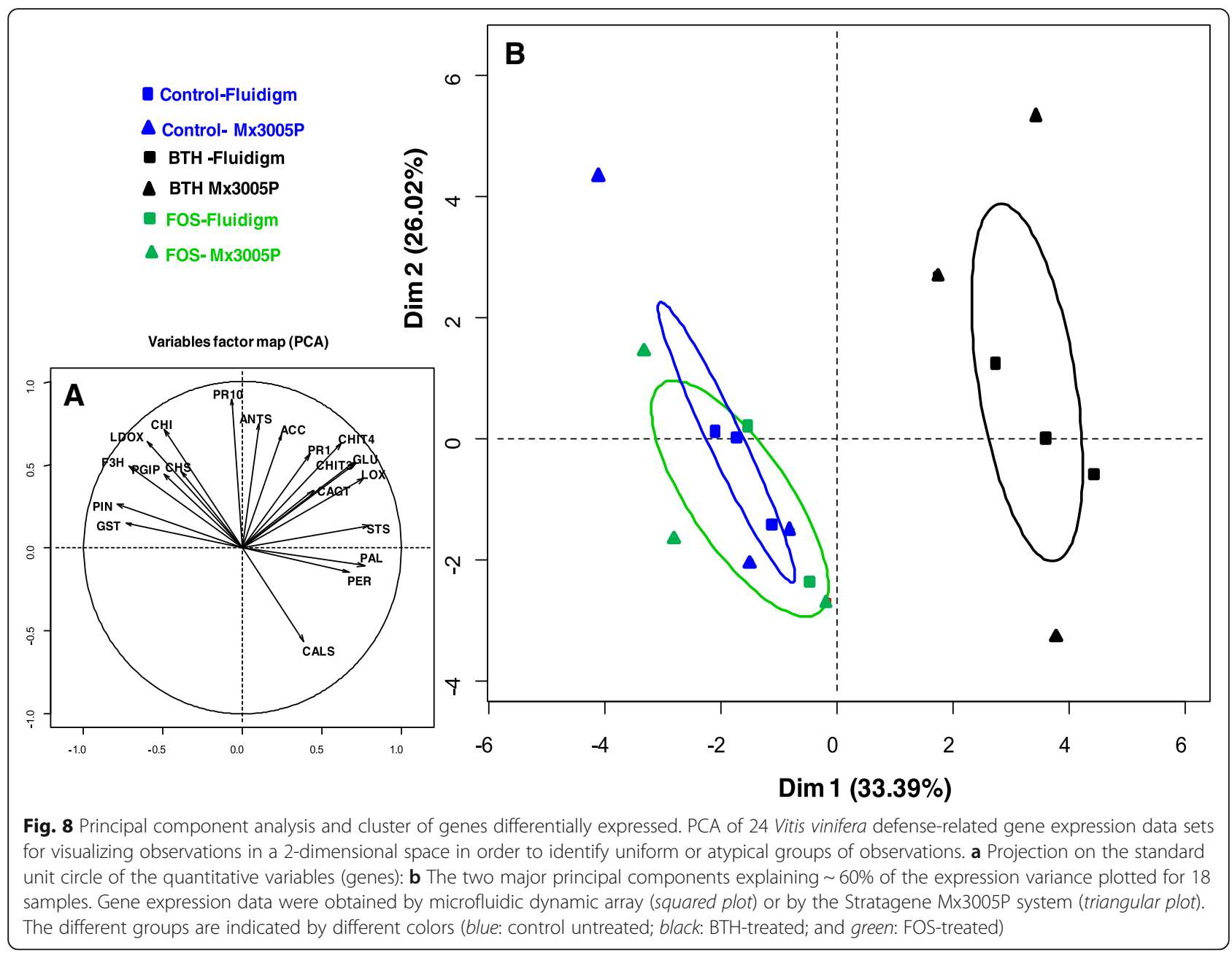

manufacturer's instructions in final volume of $900 \mu \mathrm{l}$ with a final concentration between 70 and $150 \mathrm{ng} \mu \mathrm{L}^{-1}$. The cDNAs obtained were then stored at $-20^{\circ} \mathrm{C}$. Each data point is based on three independent biological replicates (biological and non-technical replicates).

\section{Real-time qPCR with Stratagene Mx3005P system}

The expression of the selected genes was assessed by using a Stratagene Mx3005P qPCR system (Agilent technologies) with SYBR Green to detect dsDNA synthesis. For each reaction, $1 \mu \mathrm{L}$ of each primer at $1 \mu \mathrm{M}$ and $7 \mu \mathrm{L}$ of $2 \times$ MESA BLUE qPCR MasterMix Plus for SYBR $^{\circ}$ Assay Low ROX (Eurogentec) including Hot start DNA polymerase, dNTP and $\mathrm{MgCl}_{2}$ and $5 \mu \mathrm{L}$ of cDNAs, were used according to the manufacturer's instructions (350-750 ng of cDNA by well). Each PCR reaction was done in duplicate. The PCR was performed at $94{ }^{\circ} \mathrm{C}$ for $15 \mathrm{~min}$, followed by 40 cycles at $95{ }^{\circ} \mathrm{C}$ for $10 \mathrm{~s}, 55^{\circ} \mathrm{C}$ for $20 \mathrm{~s}$ and $72{ }^{\circ} \mathrm{C}$ for $20 \mathrm{~s}$. Data were analyzed with MxPro QPCR Software (Agilent technologies) as the cycle of quantification $(\mathrm{Cq})$, where the fluorescence signal of the amplified DNA intersected with the background noise. For each gene and for each modality, a mean $\mathrm{Cq}$ value was obtained.

The $\mathrm{Cq}$ values $>30$ were regarded as invalid and treated as missing data. $\Delta \mathrm{Cq}$ was obtained by subtracting the reference gene (EF1 $\gamma$ ) Cq mean from the target gene $\mathrm{Cq}$ value. The Relative Expression (RE) was calculated with the $2^{-\Delta \Delta \mathrm{Cq}}$ method for every sample where $\Delta \Delta \mathrm{Cq}$ was the $\Delta \mathrm{Cq}$ difference between two samples.

\section{Expression analysis using $\mathbf{9 6 . 9 6}$ dynamic arrays}

Eleven genes were included in the qPCR array to select the endogenous reference genes (Table 2). A 96.96 Dynamic Array IFC plate was also used to analyze the expression levels of the selected genes. The cDNA was first pre-amplified before being analyzed by qPCR with Fluidigm technology: cDNAs were diluted to $\sim 5 \mathrm{ng} \mathrm{Hl}^{-1}$ and pre-amplification was carried out by adding the reaction mixture containing 96 pairs of primers (primers pool, $50 \mathrm{mM}$ ) and the TaqMan PreAmp Master Mix (1:2, Applied Biosystems) with 14 cycles of $95{ }^{\circ} \mathrm{C}$ for $15 \mathrm{~s}$ and $60{ }^{\circ} \mathrm{C}$ for $4 \mathrm{~min}$. The pre-amplified cDNA was diluted with TE buffer (1:5) and used for qPCR analysis in a reaction 
mixture containing TaqMan Gene Expression Master Mix (Applied Biosystems), DNA Binding Dye Sample Loading Reagent (Fluidigm, Issy les Moulineaux, France) and EvaGreen (Interchim, Montlucon, France).

Real-time qPCR was performed using a BioMark ${ }^{\mathrm{TM}}$ HD system (Fluidigm Corporation). The 96.96 dynamic array was used for qPCR, according to the manufacturer's protocol (http://www.fluidigm.com/user-documents). Five $\mu \mathrm{l}$ of mixture were prepared for each sample containing 1x TaqMan Universal Master Mix (without UNG), 1x GE sample loading reagent (Fluidigm PN 85000746) and each diluted pre-amplified cDNA. The loaded chip was placed in the BioMark system for PCR at $95{ }^{\circ} \mathrm{C}$ for $10 \mathrm{~min}$, followed by 40 cycles at $95{ }^{\circ} \mathrm{C}$ for $15 \mathrm{~s}$ and $60{ }^{\circ} \mathrm{C}$ for $1 \mathrm{~min}$. The data were analyzed by using real-time PCR BioMark 2.0 Analysis software (Fluidigm Corporation, France) as the cycle of quantification (Cq) and applying the same principle of classical real-time PCR with the Stratagene MX3005P system where the fluorescence signal of the amplified DNA intersected with the background noise.

Cq values $>30$ were regarded as invalid and treated as missing data. Expression levels were calculated based on a multiple gene normalization method and using the principles and formulas of Vandesompele et al. [47]. The geometric mean of several carefully selected reference genes (Table 2) was used as an accurate normalization factor. The lowest gene stability value ( $M$ values) indicates genes with the highest gene expression stability. In all the experiments carried out with Fluidigm, all $M$ values of the 11 reference genes were collected (15 independent experiments) to obtain a data set sufficient to assess their stability.

The data were analyzed by using real-time PCR BioMark 2.0 software (Fluidigm Corporation) Analysis.

After completion of the run, a melting curve of the amplified products was determined to confirm the specificity of the reactions.

\section{Statistical analyses}

Statistical analysis was performed using the $\mathrm{R}$ statistical software ( $\mathrm{R}$ Development Core Team, 2010). AUDPC data (progress of downy mildew disease) and yield data at the harvest were compared with an analysis of variance (ANOVA) and significant differences were determined by Tukey's honest significant difference (HSD) test at the level of $P \leq 0.05$. To model the relationship between gene expressions obtained with the two platforms, a linear regression analysis was conducted and a Pearson correlation was determined at a level of $p$-value $\leq 0.05$.

Genes were observed as differentially expressed for a $p$-value $<0.05$ in rank-based nonparametric multiple comparisons with the "nparcomp" package in the R statistical software. Significant differences were determined by Dunnett's test at the level of $p \leq 0.05$.

A mathematical procedure that transforms a number of possibly correlated variables (gene expressions) into a smaller number of uncorrelated variables called principal components was performed to analyze plant defense behavior after elicitation with the "Rcmdr" package and plug-in "FactoMiner" of R statistical software.

An analysis of similarities (ANOSIM) was made to test the difference between the two methods used (Fluidigm vs Stratagene) through the use of "vegan" package of $\mathrm{R}$ statistical software.

\section{Additional files}

Additional file 1: Original sequences and/or references used to find new candidate genes involved in grapevine defenses [26, 38, 52-63]. (DOCX $42 \mathrm{~kb}$ )

Additional file 2: Protein sequence homology/orthology between Vitis and Arabidopsis and/or Malus domestica - Solanum lycopersicum - Nicotania tabaccum. (XLSX $18 \mathrm{~kb}$ )

Additional file 3: Plot of Eigen values of the principal component Most of the variance in defense gene expression data set is contained in the first two principal components with $\sim 60 \%$ of the total variability. (DOCX $76 \mathrm{~kb}$ )

Additional file 4: Relative expression data set of defense-related gene obtained in classical qPCR system (Stratagene) and in Biomark ${ }^{\circledast}$ system analyzed during this study. (XLSX $48 \mathrm{~kb}$ )

\section{Abbreviations}

ABA: Abscissic acid; AUDPC: Area under disease progress curve; $\mathrm{BBCH}$ scale: "Biologische Bundesanstalt, Bundessortenamt und CHemische Industrie"scale; BTH: S-methyl benzo[1,2,3]thiadiazole-7-carbothioate (Bion, 50WG, Syngenta); cDNA: Complementary Deoxynucleotidic acid; Cq: Cycle quantification; CTAB: Cetyl trimethylammonium bromide; EDTA: Ethylenediaminetetraacetic acid; ET: Ethylene; FOS: Fosetyl aluminium; $\mathrm{HCl}$ : Hydrogen chloride; JA: Jasmonic acid; KEGG: Kyoto encyclopedia of genes and genomes; MAPK: Mitogen-activated protein kinase; MAPKK: MAPK kinase; MAPKKK: MAPKK kinase; $\mathrm{MgCl}_{2}$ : Magnesium chloride; $\mathrm{NaCl}$ : Sodium chloride; NCBI: National Center of Biotechnology Information; NTP: Nucleotide triphosphate; PCA: Principal component analysis; PR-protein: Pathogenesis related protein; PVPP: Poly-vinyl-polypyrrolidone; RE: Relative expression; RNA: Ribonucleotidic acid; ROS: Reactive oxygen species; SA: Salicylic acid; SAR: Systemic acquired resistance; SPD: Stimulator of plant defenses; UNG: Uracil N-glycosylase

\section{Acknowledgements}

We are grateful to the Toulouse Genomics Platform (http://get.genotoul.fr) for access to the BioMarkTM HD System, to N. Ladouce (LRSV) for technical assistance, to L. Druelle for technical assistance in vineyard experiments, to $\mathrm{L}$. De Bastard from Syngenta for supplying acibenzolar-S-Methyl, and to Prof. R Cooke for reading the manuscript.

\section{Funding}

This work was supported by funding from four French ministries (FUI Neoprotec), the De Sangosse Company (Agen, France), the CIVB (Interprofessionnal Committee of Bordeaux Vines) and INRA.

\section{Availability of data and materials}

All data generated or analyzed during this study are included in this published article and its Additional files 1, 2, 3 and 4

Authors' contributions

MCD performed the research, carried out MIQE (primer efficacies and specificities, RNA integrities and accuracy, reproducibility and repeatability of RT-qPCR), RNA 
extractions and RT-qPCR with Stratagen MX3005P system, analyzed the data and wrote the paper. NM undertook bioinformatic research and carried out the primer design, BD and SV participated in developing the microfluidic 96.96 dynamic arrays (BioMark TM HD system). MFCC conceived the study, participated in its design and coordination and helped to draft the manuscript. All authors have read, corrected and approved the final manuscript.

\section{Competing interests}

The authors declare that they have no competing interests.

\section{Author details}

'INRA, UMR Santé et Agroécologie du vignoble (SAVE-1065), CS 20032, ISW, 33882 Villenave d'Ornon, CEDEX, France. ${ }^{2}$ Université de Toulouse, UPS, UMR 5546, Laboratoire de Recherche en Sciences Végétales, BP 42617, Auzeville, F-31326 Castanet-Tolosan, France. ${ }^{3}$ CNRS, UMR 5546, BP 42617, F-31326 Castanet-Tolosan, France.

\section{Received: 9 January 2016 Accepted: 16 November 2016}

\section{Published online: 22 November 2016}

\section{References}

1. Lyon GD, Newton AC. Do resistance elicitors offer new opportunities in integrated disease control strategies? Plant Pathol. 1997;46(5):636-41.

2. Walters DR, Ratsep J, Havis ND. Controlling crop diseases using induced resistance: challenges for the future. J Exp Bot. 2013;64(5):1263-80.

3. Walters $D$, Newton A, Lyon G. Induced resistance for plant defence: a sustainable approach to crop protection. Oxford: Blackwell Publishing; 2007.

4. Jones JDG, Dangl JL. The plant immune system. Nature. 2006;444(7117):323-9.

5. Walters DR, Havis ND, Sablou C, Walsh DJ. Possible trade-off associated with the use of a combination of resistance elicitors. Physiol Mol Plant Pathol. 2011;75(4):188-92.

6. Zhao J, Davis LC, Verpoorte R. Elicitor signal transduction leading to production of plant secondary metabolites. Biotechnol Adv. 2005;23(4):283-333.

7. Wang J, Pan C, Wang Y, Ye L, Wu J, Chen L, Zou T, Lu G. Genome-wide identification of MAPK, MAPKK, and MAPKKK gene families and transcriptional profiling analysis during development and stress response in cucumber. BMC Genomics. 2015;16:386.

8. Lyon G. Agents that can elicit induced resistance. In: Walters D, Newton A, Lyon $\mathrm{G}$, editors. Induced resistance for plant defence: a sustainable approach to crop protection. Oxford: Blackwell Publishing; 2007. p. 9-29.

9. Raynal G, Ravise A, Bompeix G. Action of aluminium tris-O-ethylphosphonate on pathogenicity of Plasmopara viticola and on stimulation of defence reactions of grapevine. Ann Phytopathol. 1980;12(3):163-75.

10. Dong X. SA, JA, ethylene, and disease resistance in plants. Curr Opin Plant Biol. 1998;1(4):316-23.

11. Pieterse CMJ, van Loon LC. Salicylic acid-independent plant defence pathways. Trends Plant Sci. 1999;4(2):52-8.

12. Gao Q-M, Zhu S, Kachroo P, Kachroo A. Signal regulators of systemic acquired resistance. Front Plant Sci. 2015;6:228.

13. Herrera-Vasquez A, Salinas P, Holuigue L. Salicylic acid and reactive oxygen species interplay in the transcriptional control of defense genes expression. Front Plant Sci. 2015;6:171.

14. Kunkel BN, Brooks DM. Cross talk between signaling pathways in pathogen defense. Curr Opin Plant Biol. 2002;5(4):325-31.

15. Caarls L, Pieterse CMJ, Van Wees SCM. How salicylic acid takes transcriptional control over jasmonic acid signaling. Front Plant Sci. 2015;6:170.

16. Daniel R, Guest D. Defence responses induced by potassium phosphonate in Phytophthora palmivora-challenged Arabidopsis thaliana. Physiol Mol Plant Pathol. 2006;67(3/5):194-201.

17. Iriti M, Faoro F. Benzothiadiazole (BTH) induces cell-death independant resistance in Phaseolus vulgaris against Uromyces appendicalatus. J Phytopathol. 2003;151:171-80.

18. Bompeix G, Fettouche F, Saindrenan P. Mode of action of phosethyl Al. Phytiatrie-Phytopharmacie. 1981;30(4):257-72.

19. Ahmad JN, Renaudin J, Eveillard S. Expression of defence genes in stolbur phytoplasma infected tomatoes, and effect of defence stimulators on disease development. Eur J Plant Pathol. 2014;139(1):39-51.

20. Araujo L, Silva Bispo WM, Rios VS, Fernandes SA, Rodrigues FA. Induction of the phenylpropanoid pathway by acibenzolar-S-Methyl and potassium phosphite increases mango resistance to ceratocystis fimbriata infection. Plant Dis. 2015;99(4):447-59.
21. Barilli E, Rubiales D, Amalfitano C, Evidente A, Prats E. BTH and BABA induce resistance in pea against rust (Uromyces pisi) involving differential phytoalexin accumulation. Planta. 2015;242(5):1095-106.

22. Gordy JW, Leonard BR, Blouin D, Davis JA, Stout MJ. Comparative effectiveness of potential elicitors of plant resistance against spodoptera frugiperda (J. E. Smith) (Lepidoptera: Noctuidae) in four crop plants. Plos One. 2015;10(9):e0136689.

23. Wang K, Liao Y, Cao S, Di H, Zheng Y. Effects of benzothiadiazole on disease resistance and soluble sugar accumulation in grape berries and its possible cellular mechanisms involved. Postharvest Biol Technol. 2015;102:51-60.

24. Bressan A, Purcell AH. Effect of benzothiadiazole on transmission of Xdisease phytoplasma by the vector Colladonus montanus to Arabidopsis thaliana, a new experimental host plant. Plant Dis. 2005;89(10):1121-4.

25. Brisset MN, Cesbron S, Thomson SV, Paulin JP. Acibenzolar-S-methyl induces the accumulation of defense-related enzymes in apple and protects from fire blight. Eur J Plant Pathol. 2000;106(6):529-36.

26. Dufour MC, Lambert C, Bouscaut J, Merillon JM, Corio-Costet MF. Benzothiadiazole-primed defence responses and enhanced differential expression of defence genes in Vitis vinifera infected with biotrophic pathogens Erysiphe necator and Plasmopara viticola. Plant Pathol. 2013;62(2):370-82.

27. Dufour M-C, Corio-Costet M-F. Variability in the sensitivity of biotrophic grapevine pathogens (Erysiphe necator and Plasmopara viticola) to acibenzolar-S methyl and two phosphonates. Eur J Plant Pathol. 2013;136(2):247-59.

28. Siegrist L, Glenewinkel D, Kolle C, Schmidtke M. Chemically induced resistance in green bean against bacterial and fungal pathogens. Z Pflanzenkrankh Pflanzenschutz. 1997;104(6):599-610.

29. Sticher L, Mauch-Mani B, Metraux JP. Systemic acquired resistance. Annu Rev Phytopathol. 1997:35:325-70.

30. Tally A, Oostendorp M, Lawton K, Staub T, Bassi B. Commercial development of elicitors of induced resistance to pathogens. In: Agrawal A, Tuzun S, Bent E, editors. Induced plant defenses against pathogens and herbivores: biochemistry, ecology, and agriculture. American Pthytopatological Society (St Paul MN: APS Press); 1999. p. 357-369.

31. Friedrich L, Lawton K, Ruess W, Masner P, Specker N, Gut Rella M, Meier B, Dincher $\mathrm{S}$, Staub T, Uknes $\mathrm{S}$, et al. A benzothiadiazole derivative induces systemic acquired resistance in tobacco. Plant J. 1996;10(1):61-70.

32. Fenn ME, Coffey MD. Studies on the in vitro and in vivo antifungal activity of fosetyl-Al and phosphorous acid. Phytopathology. 1984;74(5):934-6.

33. Massoud K, Barchietto T, Le Rudulier T, Pallandre L, Didierlaurent L, Garmier M, Ambard-Bretteville F, Seng J-M, Saindrenan P. Dissecting phosphiteinduced priming in Arabidopsis infected with Hyaloperonospora arabidopsidis. Plant Physiol. 2012;159(1):286-98.

34. Jackson TJ, Burgess T, Colquhoun I, Hardy GES. Action of the fungicide phosphite on Eucalyptus marginata inoculated with Phytophthora cinnamomi. Plant Pathol. 2000:49(1):147-54.

35. Nemestothy GS, Guest DI. Phytoalexin accumulation, phenylalanine ammonia lyase activity and ethylene biosynthesis in fosetyl-Al treated resistant and susceptible tobacco cultivars infected with Phytophthora nicotianae var. nicotianae. Physiol Mol Plant Pathol. 1990;37(3):207-19.

36. Saindrenan P, Barchietto T, Avelino J, Bompeix G. Effects of phosphite on phytoalexin accumulation in leaves of cowpea infected with Phytophthoracryptogea. Physiol Mol Plant Pathol. 1988;32(3):425-35.

37. Saindrenan P, Barchietto T, Bompeix G. Effects of phosphonate on the elicitor activity of culture filtrates of Phytophthora-cryptogea in Vignaunguiculata. Plant Sci. 1990;67(2):245-51.

38. de Bernonville TD, Marolleau B, Staub J, Gaucher M, Brisset M-N. Using molecular tools to decipher the complex world of plant resistance inducers: an apple case study. J Agric Food Chem. 2014;62(47):11403-11.

39. Polesani M, Bortesi L, Ferrarini A, Zamboni A, Fasoli M, Zadra C, Lovato A, Pezzotti M, Delledonne M, Polverari A. General and species-specific transcriptional responses to downy mildew infection in a susceptible (Vitis vinifera) and a resistant (V. riparia) grapevine species. BMC Genomics. 2010;11:117.

40. Devonshire AS, Sanders R, Wilkes TM, Taylor MS, Foy CA, Huggett JF. Application of next generation $\mathrm{QPCR}$ and sequencing platforms to mRNA biomarker analysis. Methods. 2013;59(1):89-100.

41. Jaillon O, Aury J-M, Noel B, Policriti A, Clepet C, Casagrande A, Choisne N, Aubourg S, Vitulo N, Jubin C, et al. The grapevine genome sequence suggests ancestral hexaploidization in major angiosperm phyla. Nature. 2007:449(7161):463-7.

42. Chenna R, Sugawara H, Koike T, Lopez R, Gibson TJ, Higgins DG, Thompson JD. Multiple sequence alignment with the Clustal series of programs. Nucleic Acids Res. 2003;31(13):3497-500. 
43. Ye J, Coulouris G, Zaretskaya I, Cutcutache I, Rozen S, Madden TL. PrimerBLAST: A tool to design target-specific primers for polymerase chain reaction. BMC Bioinformatics. 2012;13(1):1.

44. Hruz T, Laule O, Szabo G, Wessendorp F, Bleuler S, Oertle L, Widmayer P, Gruissem W, Zimmermann P. Genevestigator v3: a reference expression database for the meta-analysis of transcriptomes. Adv Bioinforma. 2008; 2008:420747.

45. Pfaffl MW. A new mathematical model for relative quantification in real-time RT-PCR. Nucleic Acids Res. 2001;29(9):e45.

46. Thorsen T, MaerkI SJ, Quake SR. Microfluidic large-scale integration. Science. 2002:298(5593):580-4.

47. Vandesompele J, De Preter K, Pattyn F, Poppe B, Van Roy N, De Paepe A, Speleman F. Accurate normalization of real-time quantitative RT-PCR data by geometric averaging of multiple internal control genes. Genome Biol. 2002;3(7):RESEARCH0034-RESEARCH0034.

48. Simko I, Piepho H-P. The area under the disease progress stairs: calculation, advantage, and application. Phytopathology. 2012;102(4):381-9.

49. Giannakis C, Bucheli CS, Skene KGM, Robinson SP, Scott NS. Chitinase and b 1,3-glucanase in grapevine leaves: a possible defence against powdery mildew infection. Aust J Grape Wine Res. 1998;4:14-22.

50. Kortekamp A. Expression analysis of defence-related genes in grapevine leaves after inoculation with a host and a non-host pathogen. Plant Physiol Biochem. 2006;44(1):58-67.

51. Bustin SA, Benes V, Garson JA, Hellemans J, Huggett J, Kubista M, Mueller R, Nolan T, Pfaffl MW, Shipley GL, et al. The MIQE guidelines: minimum information for publication of quantitative real-time PCR experiments. Clin Chem. 2009;55(4):611-22.

52. Reid KE, Olsson N, Schlosser J, Peng F, Lund ST. An optimized grapevine RNA isolation procedure and statistical determination of reference genes for real-time RT-PCR during berry development - art. no. 27. BMC Plant Biol. 2006;6:27.

53. Hong SM, Bahn SC, Lyu A, Jung HS, Ahn JH. Identification and testing of superior reference genes for a starting pool of transcript normalization in Arabidopsis. Plant Cell Physiol. 2010;51(10):1694-706.

54. Robinson SP, Jacobs AK, Dry IB. A class IV chitinase is highly expressed in grape berries during ripening. Plant Physiol. 1997;114(3):771-8.

55. Sels J, Mathys J, De Coninck BMA, Cammue BPA, De Bolle MFC. Plant pathogenesis-related (PR) proteins: A focus on PR peptides. Plant Physiol Biochem. 2008:46(11):941-50.

56. Tornero P, Conejero V, Vera P. Primary structure and expression of a pathogen-induced protease (PR-P69) in tomato plants: Similarity of functional domains to subtilisin-like endoproteases. Proc Natl Acad Sci U S A. 1996;93(13):6332-7.

57. Ponstein AS, Bresvloemans SA, Selabuurlage MB, Vandenelzen PJM, Melchers LS, Cornelissen BJC. A novel pathogen-inducible and woundinducible tobacco (Nitoctiana tabacum) protein with antifungal activity. Plant Physiol. 1994;104(1):109-18.

58. Hu X, Bidney DL, Yalpani N, Duvick JP, Crasta O, Folkerts O, Lu GH Overexpression of a gene encoding hydrogen peroxide-generating oxalate oxidase evokes defense responses in sunflower. Plant Physiol. 2003;133(1):170-81.

59. Schmidlin L, Poutaraud A, Claudel P, Mestre P, Prado E, Santos-Rosa M, Wiedemann-Merdinoglu S, Karst F, Merdinoglu D, Hugueney P. A stressinducible resveratrol O-Methyltransferase involved in the biosynthesis of pterostilbene in grapevine. Plant Physiol. 2008;148(3):1630-9.

60. Bezier A, Lambert B, Baillieul F. Cloning of a grapevine Botrytis-responsive gene that has homology to the tobacco hypersensitivity-related hsr203J. J Exp Bot. 2002;53(378):2279-80.

61. Wu J, Zhang Y, Zhang H, Huang H, Folta KM, Lu J. Whole genome wide expression profiles of Vitis amurensis grape responding to downy mildew by using Solexa sequencing technology. BMC Plant Biol. 2010;10(1):1.

62. Laudert D, Pfannschmidt U, Lottspeich F, HollanderCzytko H, Weiler EW. Cloning, molecular and functional characterization of Arabidopsis thaliana allene oxide synthase (CYP 74), the first enzyme of the octadecanoid pathway to jasmonates. Plant Mol Biol. 1996;31(2):323-35.

63. Marchive C, Mzid R, Deluc L, Barrieu F, Pirrello J, Gauthier A, Corio-Costet MF, Regad F, Cailleteau B, Hamdi S, et al. Isolation and characterization of a Vitis vinifera transcription factor, VvWRKY1, and its effect on responses to fungal pathogens in transgenic tobacco plants. J Exp Bot. 2007;58(8):1999-2010.

\section{Submit your next manuscript to BioMed Central and we will help you at every step:}

- We accept pre-submission inquiries

- Our selector tool helps you to find the most relevant journal

- We provide round the clock customer support

- Convenient online submission

- Thorough peer review

- Inclusion in PubMed and all major indexing services

- Maximum visibility for your research

Submit your manuscript at www.biomedcentral.com/submit
Biomed Central 